CuPAUAM. 15-1988

\title{
MATERIALES CERAMICOS DE LA SEGUNDA EDAD DEL HIERRO DEL CANTAMENTO DE LA PEPINA (FREGENAL DE LA SIERRA, BADAJOZ)
}

\author{
ALONSO RODRÍGUEZ DíaZ \\ Universidad de Extremadura \\ LUIS BERROCAL RANGEL \\ Universidad Autónoma de Madrid
}

\section{RESUMEN}

Este trabajo presenta el estudio general de una serie de materiales recogidos por los autores, principalmente, entre los destrozos clandestinos realizados en una supuesta necrópolis del Hierro Dos Alentejano-Extremeño. La aportación principal estriba en ser uno de los primeros conjuntos materiales conocidos en este ámbito cultural y geográfico, así como en el porcentaje de piezas decoradas.

\section{SUMMARY}

On these pages, it is analysed a group of ceramic and metal artefacts from furtives' damages, mainly, in a Second Iron Age necropolis of Southwestern Peninsula. It has a special interest for being one of first known groups from this geographical and ethnological region and, also for the big ratio in decorated pieces.

\section{Situación y características del yacimiento}

La situación geográfica del llamado Cantamento de la Pepina responde a las coordenadas $38^{\circ} 15^{\prime} 5^{\prime \prime} \mathrm{N}$. 6 $32^{\circ} 0^{\prime \prime} \mathrm{O}$, del MTN, hoja 875 y pertenece administrativamente al término municipal de Frenegal de la Sierra (Badajoz). En línea recta, se localiza a poco más de 13 $\mathrm{Km}$. al nordeste de dicha población y el mejor acceso a este lugar se realiza por el camino de Valencia del Ventoso a Frenegal, desviándose a la derecha por el cortijo de Maravés.

Su existencia nos fue dada a conocer por Isidoro de la Maya, Isidro Amaya, Diego Peral, J. Manuel y Magdalena de la Fuente, entusiastas aficionados de Valencia del Ventoso y Zafra, 
de los que siempre recibimos ayuda e información desinteresada, gracias a la que hemos podido recuperar los materiales presentados, de las actuaciones y desidias de expoliadores clandestinos.

El asentamientos ocupa dos elevaciones que forman parte marginal de una estribación con cota máxima en 551 m. s.n.m. (Cerro de los Castellares), siendo el desnivel resultante entre la cima de dicha elevación y el terreno circundante entre ochenta y doscientos metros. Las dos alturas, que denominamos Cantamentos 1 y 2, tienen las cotas de 463 y $481 \mathrm{~m}$. s.n.m. respectivamente y están separadas por una vaguada, de veinte a treinta metros de profundidad, en la que parece localizada una posible necrópolis.

El lugar, que es ciertamente un laberinto de pequeñas estribaciones, está plagado de grandes afloramientos de rocas ácidas (fundamentalmente granitos) y presenta un suelo Xero-ranker bastante erosionado que sólo es explotable en calidad de pastizales durante los meses de primavera.

Sin embargo la zona es especialmente rica en aguas, siendo frecuentes las correntías excepto en verano. El yacimiento está bordeado por un par de pequeños arroyos que desembocan en el Pedruégano, un kilómetro al Oeste.

El valor estratégico del lugar debe entenderse respecto al control del paso de los ríos Pedruégano y Ardila por la actual Cañada Real de Valencia del Ventoso, que comunica el poblado con el Castrejón de Bodonal por el Sur y con el Cerro de S. Pedro y el Castrejón de Valencia, por el Este. Pero además, el Cantamento de la Pepina ocupa el lugar de entrada a un área especialmente tortuosa, flanco meridional del valle medio del Ardila, especialmente rico en yacimientos mineros bajo el dominio de poblados como el Castillo de Jerez, el Cañuelo o el Guruviejo (Rodríguez Díaz, 1987; Berrocal, 1988).

Sin duda estamos ante uno de los yacimientos con materiales más esclarecedores e importantes de esta Comarca bañada por el río Ardila. Posiblemente por ello o por haberse localizado lo que parece con claridad la única necrópolis que conocemos, los clandestinos han actuado sobre él arrasando literalmente algunas de sus zonas, como el supuesto cementerio, durante los dos últimos años. Nuestra labor, coordinada con los colaboradores citados ha llegado hasta la denuncia y recuperación de un lote de piezas cerámicas completas que estaban siendo substraidas por dos clandestinos sevillanos. Durante dos años hemos recogido, pacientemente, los materiales abandonados y destrozados por estas infames actuaciones, habiendo estudiado para este trabajo un total de doscientas cincuenta piezas individualizadas, del medio millar recopilado. La mayoría de este material procede de la supuesta necrópolis y sólo una pequeña proporción, del asentamiento n. ${ }^{\circ} 1$, el más meridional, que es el que estudiamos en profundidad.

El Cantamento de la Pepina 1 ocupa un cerrete alargado que sobresale del macizo principal por su flanco oriental y alcanza la cota de $463 \mathrm{~m}$. s.n.m. Se trata de un poblado amurallado, con ejes de $250 \times 60 \mathrm{~m}$. aproximadamente. Se extiende por la plataforma artificial de la cima y está bordeado, longitudinalmente, por un recinto murado, conservado en algunos de sus tramos hasta la altura de un metro y que arranca directamente de la roca madre. La anchura de esta estructura oscila entre 1,5 y $2 \mathrm{~m}$. y el aparejo utilizado es granítico, de diverso tamaño, más o menos desbastado al exterior y unido a seco.

Por razones de rentabilidad a menudo se aprovechan los grandes afloramientos rocosos. 
En el flanco occidental se observan los restos de una bastión rectangular de dimensiones imprevisibles sin excavación, mientras que en el oriental, el más alto, se documentan dos estructuras cónicas, similares a las de los castros vecinos de La Martela (Enríquez y Rodríguez, 1988, 113-128) y Capote (Berrocal, 1988-a, 15 y 50), una de las cuales está casi totalmente destruida, con un diámetro en la base cercano a los diez metros. En este flanco la pendiente es sumamente escarpada, formando grandes paredes rocosas, sobre las que se observa una alineación de bloques ciclópeos de más de dos metros de altura, que pueden haber sido tallados, bien por la acción natural o por la mano del hombre, sobre la misma roca madre. Los cimientos del recinto murado se han localizado con claridad inmediatamente encima y paralelos a la citada alineación "megalítica".

\section{Los materiales arqueológicos}

Ante la procedencia y obtención de estos materiales, esencialmente cerámicos, abandonados por las numerosas actuaciones clandestinas, parece ocioso todo intento de extraer conclusiones más allá de la confirmación de la presencia de las formas y decoraciones. Sin embargo debemos especificar que, para lograr una muestra lo más significativa posible, siempre se recogieron las piezas sin atender exclusivamente a las decoraciones y procurando que las cerámicas lisas no fueran marginadas. No obstante esto no quiere decir que no existiese tal selección, más o menos voluntaria, ni que del muestreo se puedan obtener conclusiones tan válidas como las que pueden extraerse de una excavación.

Sí es cierto que la presencia de las cerámicas decoradas es notable, mucho mayor que las conocidas en otros yacimientos, fenómeno explicable si se tiene encuenta que el $90 \%$ de los fragmentos cerámicos proceden de lo que parece ser una necrópolis, en este caso la única documentada en toda la Comarca (Berrocal, 1989).

El estudio de los materiales cerámicos se ha abordado agrupándolos en diversas categorías:

II.1. Cerámicas a mano, notablemente representadas en este yacimiento, abarca aproximadamente $40 \%$ del total. De ellas, sobre $16 \%$ presentan decoración.

En líneas generales, los fragmentos lisos están realizados con arcillas escasamente depuradas, con desgrasantes medios y gruesos, cocciones ocuras y acabados superficiales alisados e incluso sin tratar. Por su parte, los recipientes decorados poseen pastas más decantadas, cocción reductora y acabados superficiales espatulados, pulidos y bruñidos.

La decoración, en la mayor parte de los casos, suele situarse a la altura del hombro, en ocasiones marcado por suave carena, o en el propio galbo del cuerpo, casi siempre al exterior. Las técnicas decorativas son la aplicada o plástica (Figs. 3, 4, 10 y 11), en forma de cordones horizontales y mamelones cónicos y tubulares; la inciso e impresa (Figs. 3, 5, 6, 7, 8, 12 y 13) y la estampillada (Figs. 13 y 18), a menudo asociadas entre sí.

En este apartado hay que señalar que, mediante la técnica inciso-impresa, los motivos más desarrollados son los espigados simples y/o líneas en zig-zag — simples o múltiples-, triángulos rellenos de paralelas, pequeñas incisionnes oblicuas que recuerdan a las llamadas «folhas d'acaçia», ungulaciones y guirnaldas, líneas de oquedades y diversos motivos geométricos 
impresos a base de finas púas de peine. Entre las piezas estampilladas señalamos «bastoncillos", "meandros", círculos concéntricos y "escutiformes triangulares" (Fig. 18 a, b, d y e).

Las formas, según las piezas completas y reconstruibles, así como algunos fragmentos de interés, pueden definirse en algunos tipos principales (Fig. 1):

1. Vasos troncocónicos, de base generalmente plana, borde ocasionalmente perforado por uno o dos orificios y labio plano o apuntado al interior (Fig. 1.I y 2.

2. Cuencos de perfil semiesférico, base plana y borde de labio curvo, apuntado o plano (Fig. 1.II).

3. Grandes recipientes de paredes reentrantes y perfil curvo o bitroncocónico, a menudo con algún mamelón junto en el borde (Fig.: 1.III y 14 a).

4. Vasos de diversos tamaños, globulares de cuello destacado y borde ligeramente saliente (Fig. 1.IV; 3 y 4). Suelen ir decorados con cordones incisos e impresos.

5. Vasos de perfil en "S" (Fig. 1.V.a) o con ligera carena alta u hombro marcado (Fig. 1.V.b), pié generalmente destacado y borde ligeramente exvasado. A menudo presentan cuatro o más mamelones tubulares verticales y muestran el inicio del cuerpo, bajo el hombro, decorado con impresiones, incisiones y estampillas (Figs. 5, 6, 7, 8, 9, 13 y 18 d y e).

En cuanto al tamaño, se observan dos grupos destacados, uno menor con diámetros en torno a los 8 y $12 \mathrm{~cm}$. y otro mayor, entre 15 y $20 \mathrm{~cm}$.

Una pieza excepcional, por su decoración, es una pequeña urnita, cuyo cuerpo muestra al menos dos filas horizontales de mamelones, los superiores con forma de gancho orientado hacia abajo y sobre ellos, justo bajo la nave carena del hombro, una sucesión de pequeñas incisiones oblicuas, finas y profundas. Su pasta es poco compacta, de tonalidad ocre y superficies alisadas (Fig. 9 c).

6. Recipientes de tamaño mediano que tienen como rasgo definitorio el presentar perforaciones de diverso tipo en el galbo. Se trata de los denominados "vasos calados, fenestrados o quemadores" (Figs. 1.VI a, b y c; 10). Son frecuentes tanto las formas lisas como decoradas con incisiones. Poseen todos perforaciones triangulares, si bien cabría distinguir, como posibles variantes, entre aquellos de perfil ovoide y ligeramente cerrado y lo que parecen cuencos semiesféricos. Las bases suelen ser cóncavas o realzadas y paralelepípedas con prismas que conforman vanos rectangulares (Fig. 9 d).

7. Recipiente de gran tamaño con perfil de saco, cuello tímidamente indicado, borde normal y ligeramente saliente, con un diámetro de boca que oscila en torno a los $40 \mathrm{cms}$. La inclinación, más o menos abierta, del cuello y el remate del borde, plano o redondeado, establecen las variantes por ahora observables (Fig. 1.VII a y b).

8. Recipiente de tamaño grande con perfil globular, boca en torno a los $30 \mathrm{cms}$. de diámetro, borde ligeramente exvasado y redondeado, cuello desarrollado y base posiblemente plana (Fig. 1.VIII).

En cuanto a la valoración cultural de estos materiales, a pesar de que ya uno de nosotros haya ofrecido un avance de su estudio (Berrocal, 1989), hemos de significar que habitualmente venimos considerado estas cerámicas como una producción local con una tradición cultural 

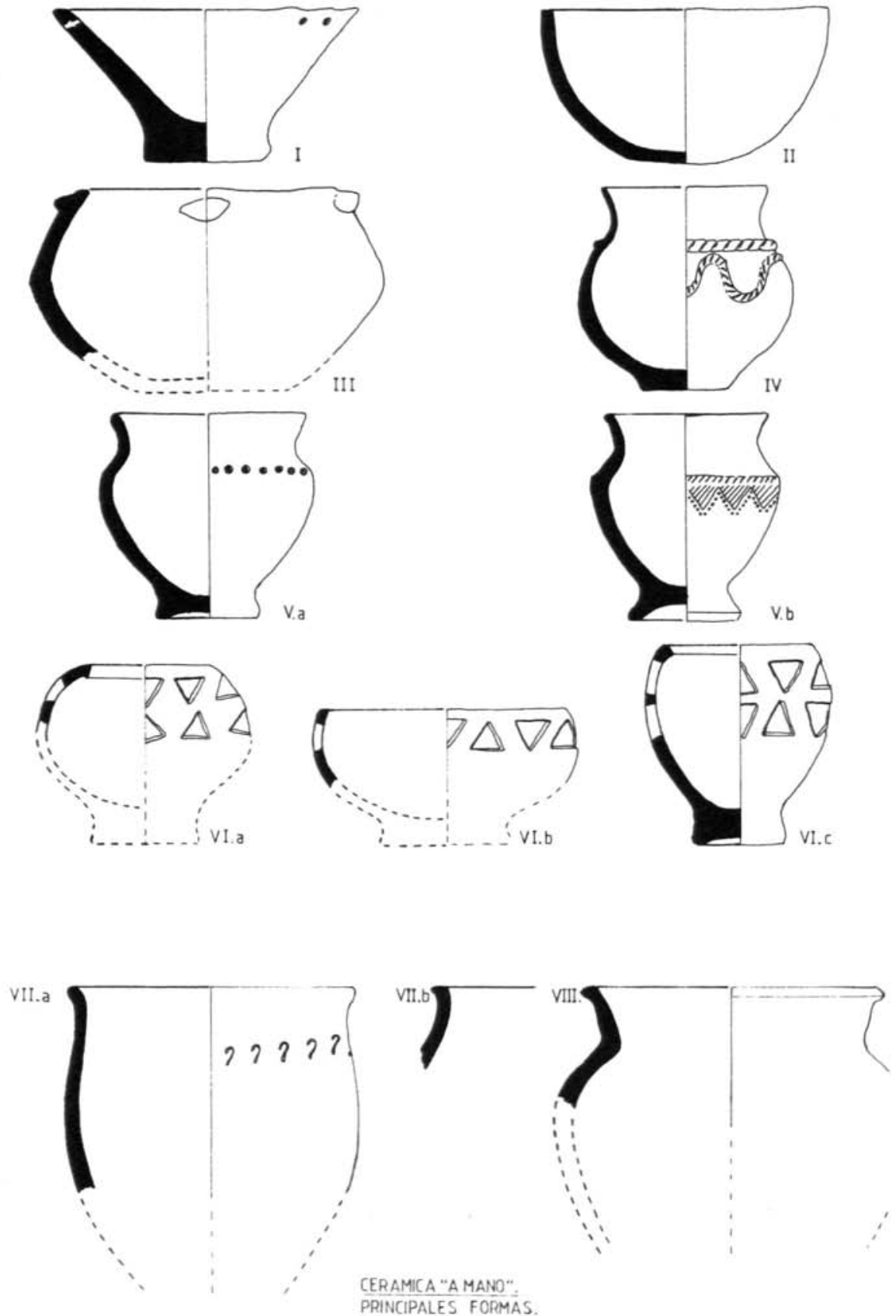

PPINCIPALES FORMAS

FIG. 1. - Principales formas de cerámica «a mano». 

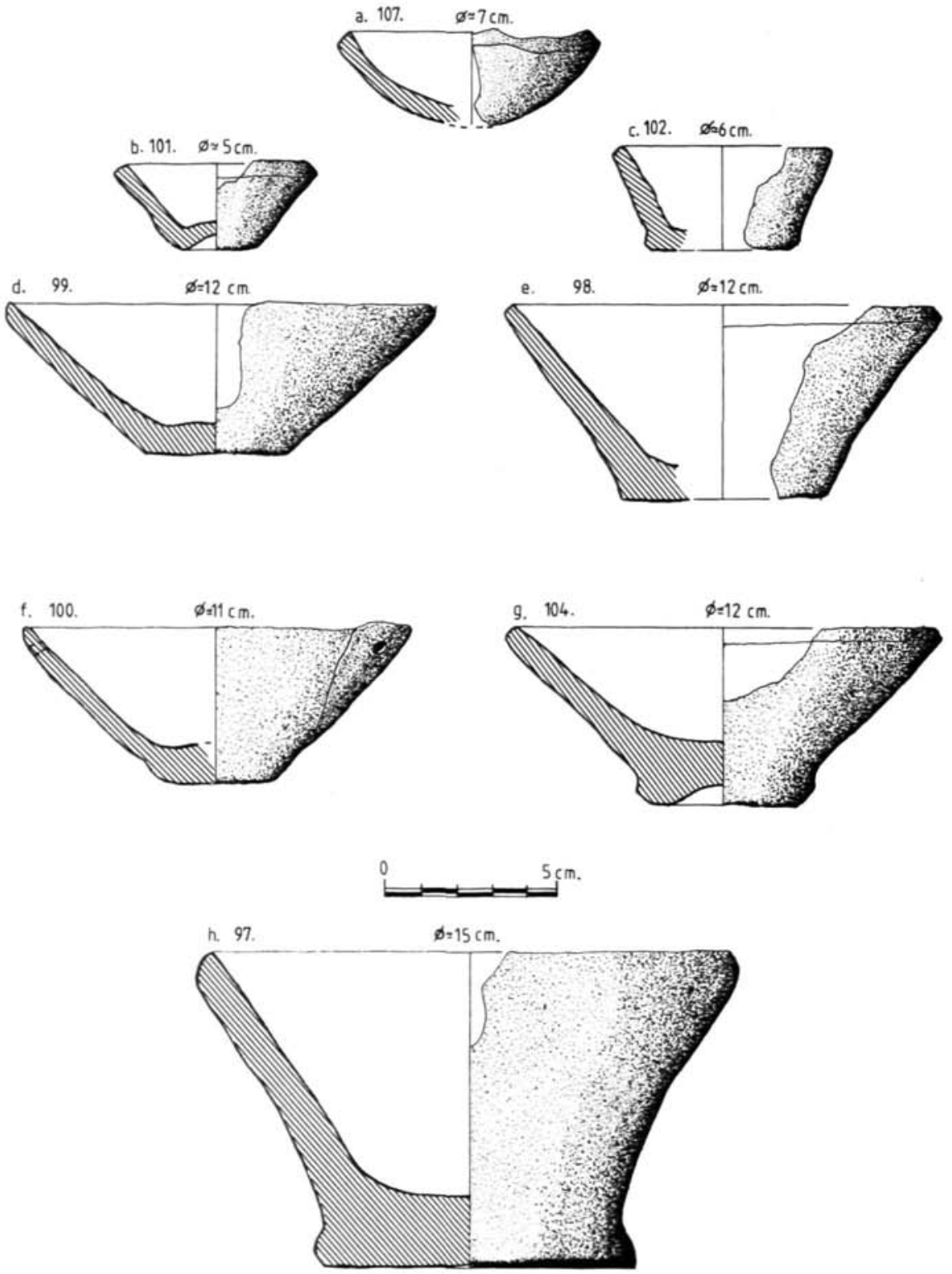

FIG. 2. - Vasos troncocónicos «a mano". 

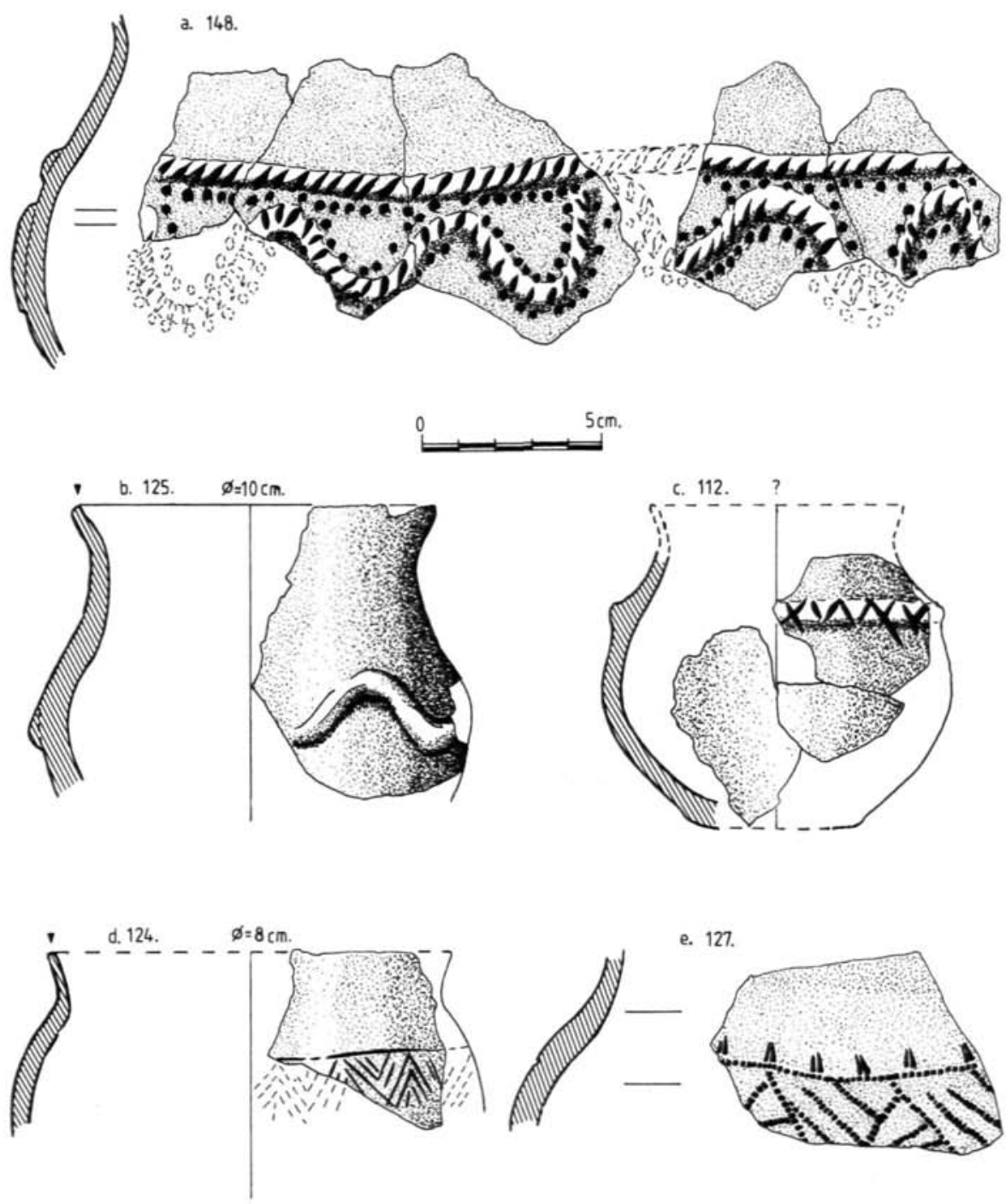

e. 127 .

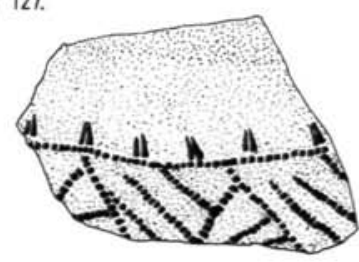

FIG. 3. - Vasijas «a mano», con decoración plástica, incisa, impresa y «puntillada». 

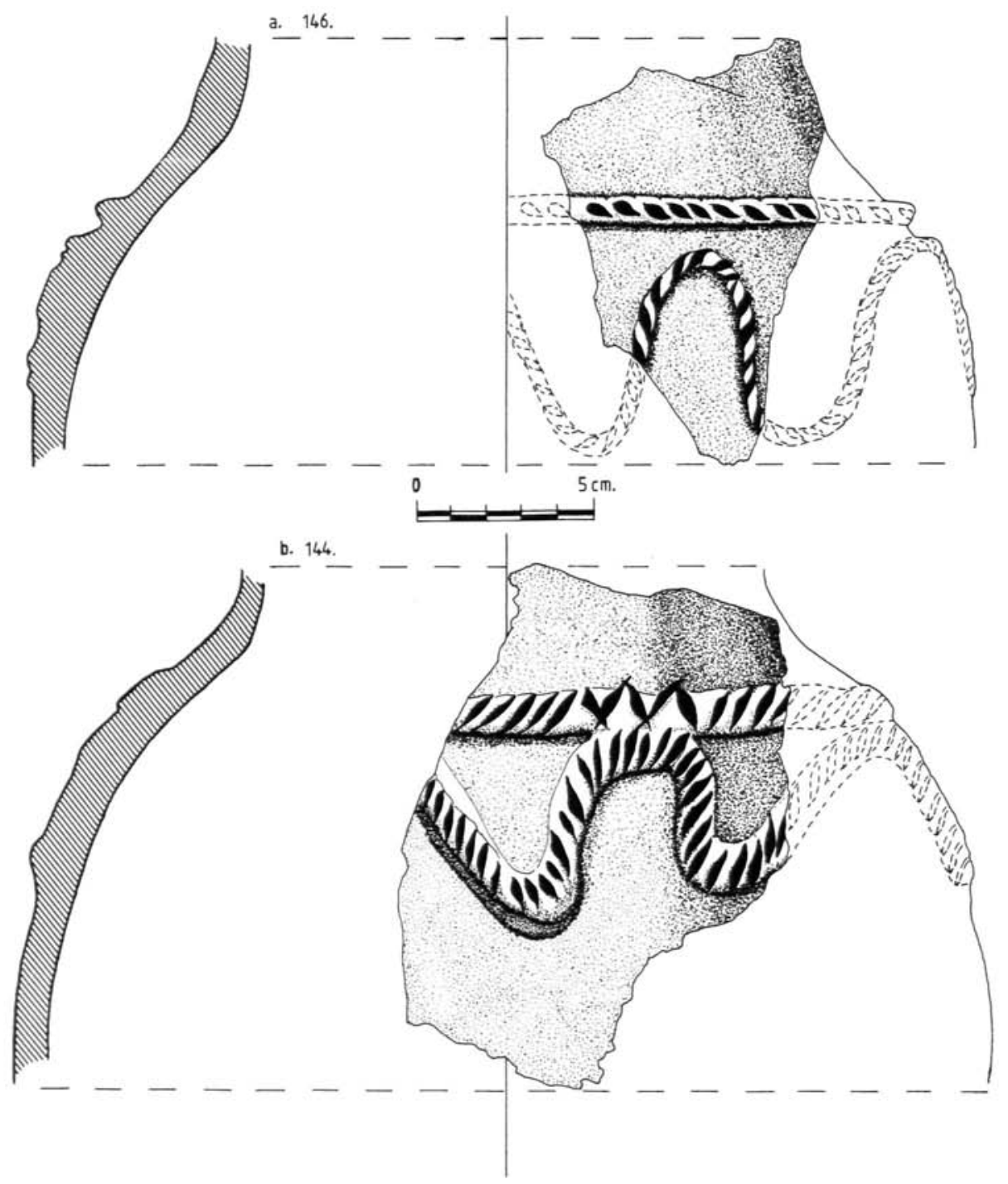

FIG. 4. - Grandes vasijas «a mano" decoradas con cordones incisos. 

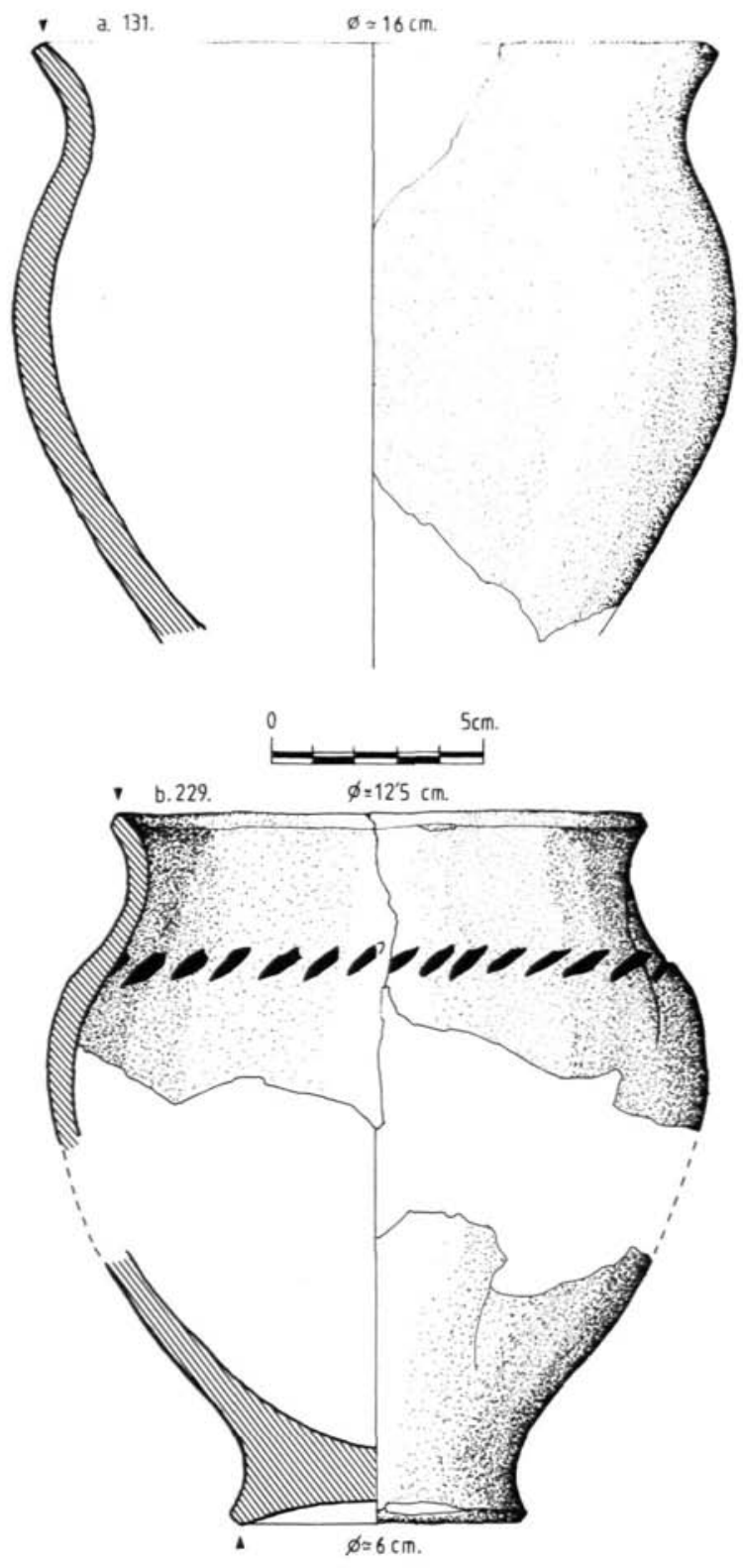

FIG. 5. - Urnas «a mano» de perfil en « $\mathrm{S}$ * y hombro con incisiones. 

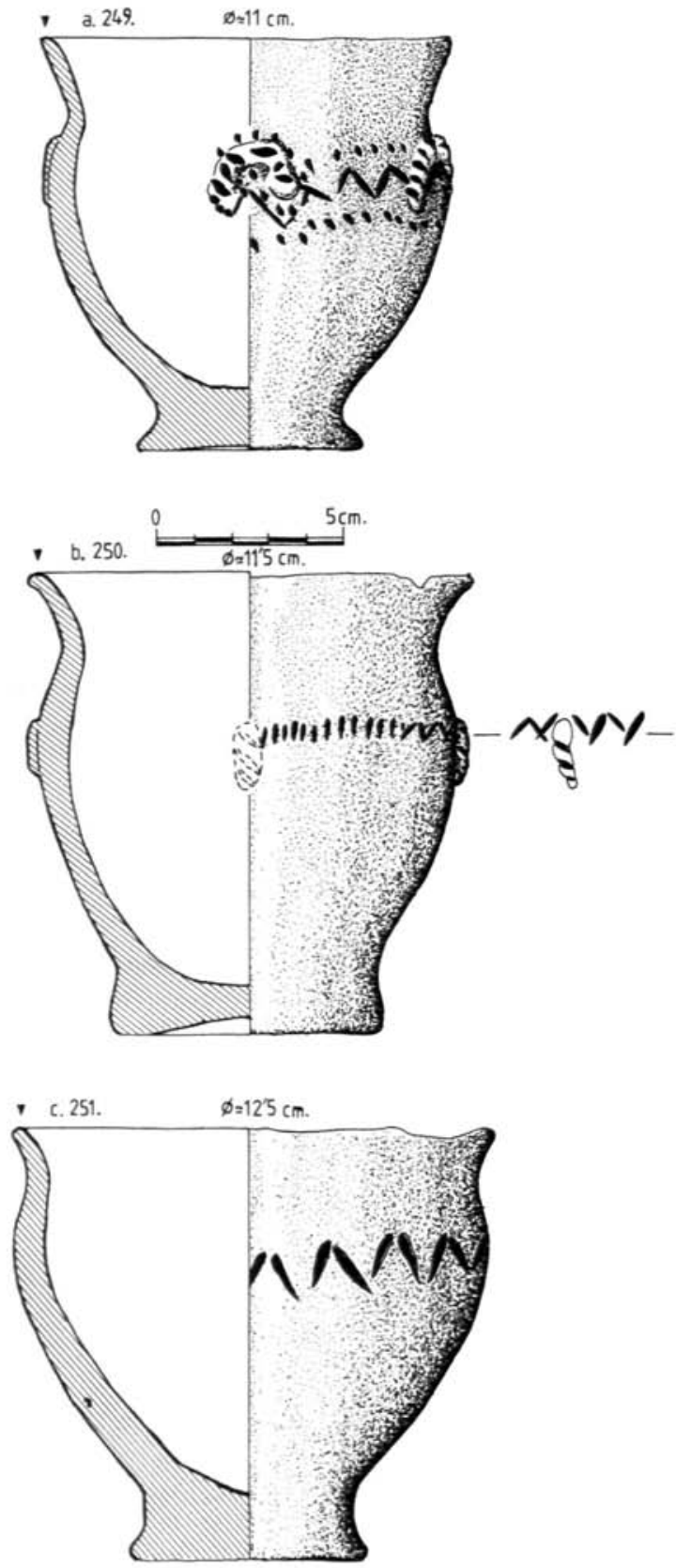

FIG. 6. - Urnitas "a mano" incisas, aplicadas e impresas. 

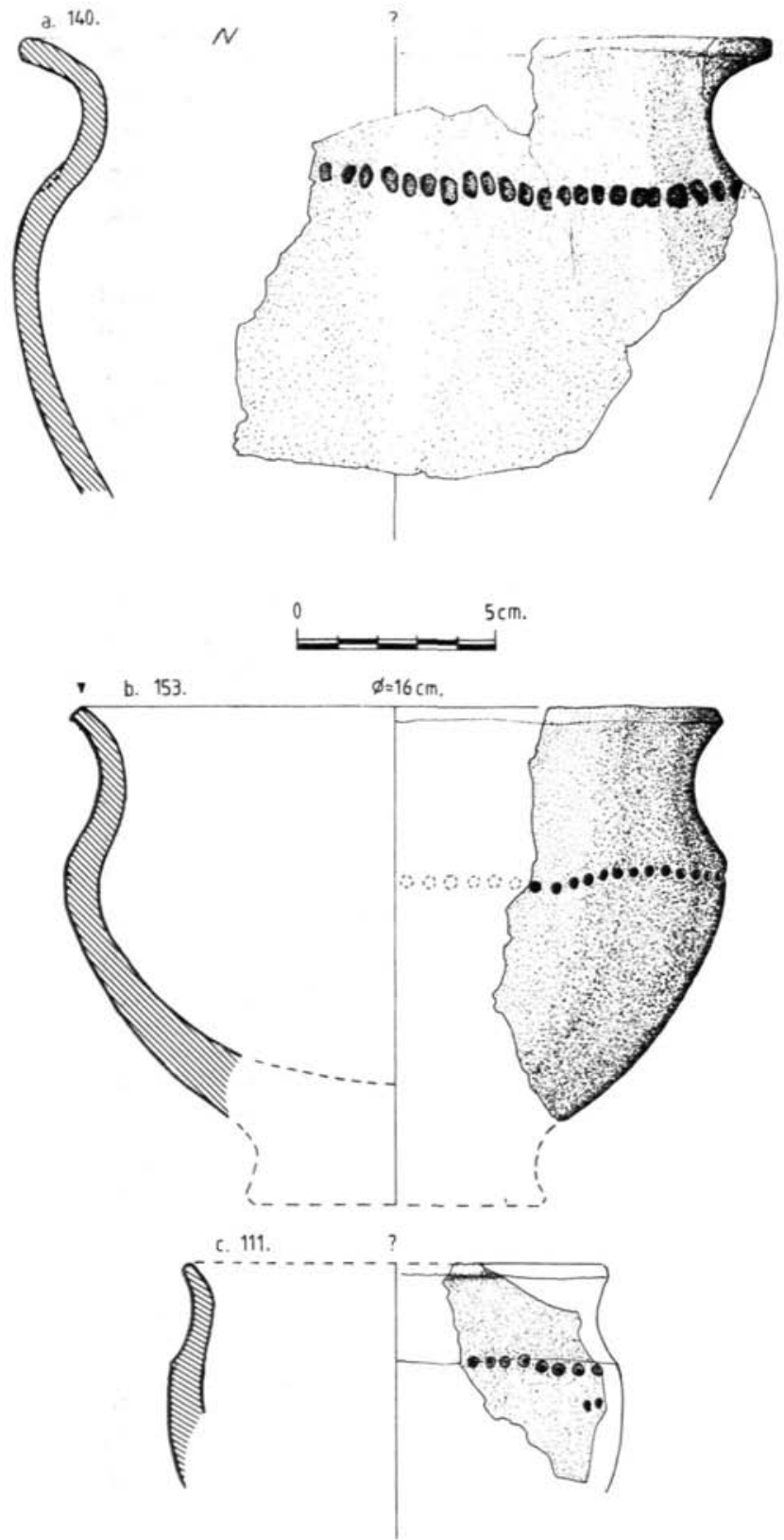

FIG. 7. - Unas «a mano» con el hombro marcado e impreso. 


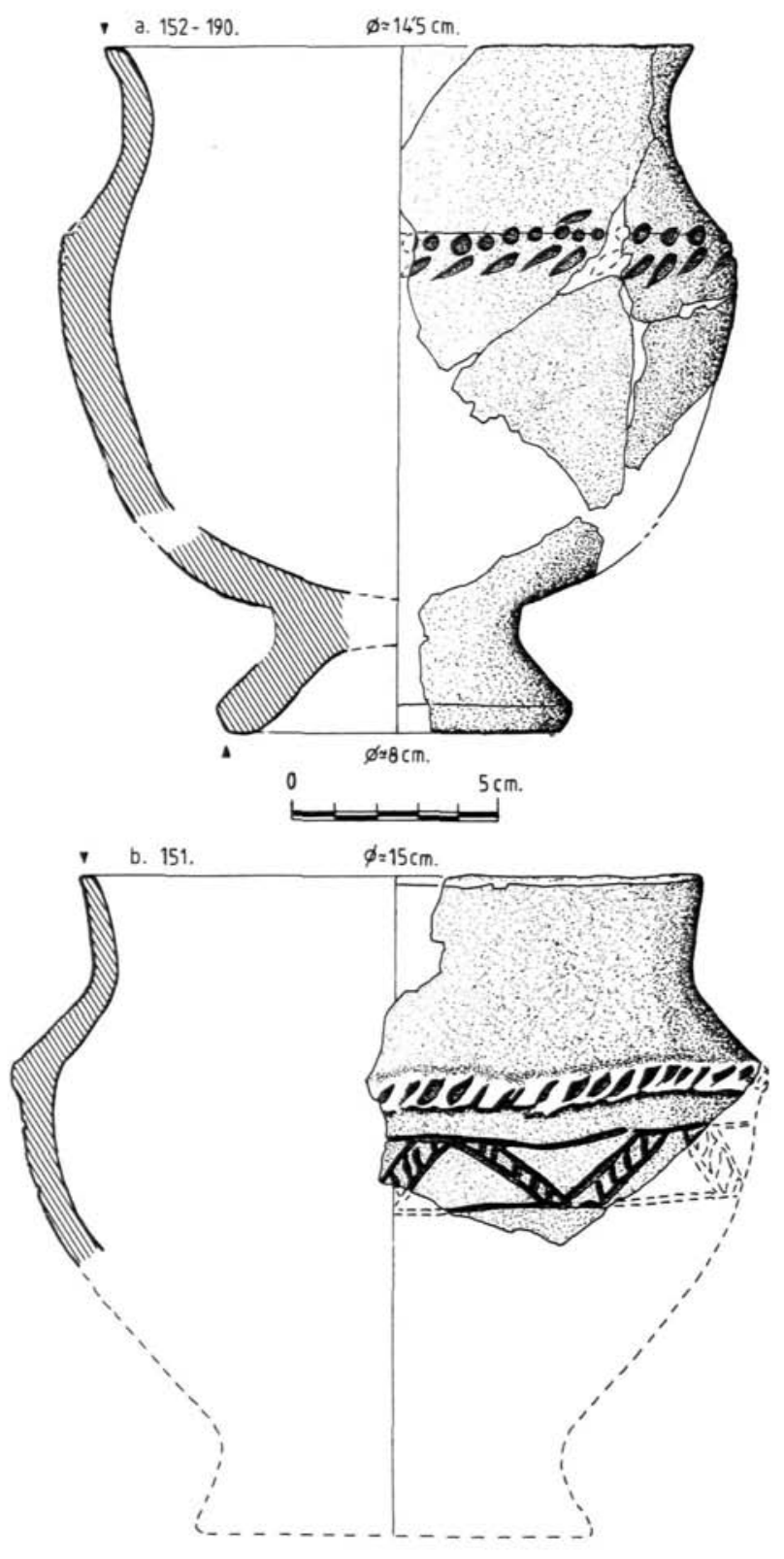

FIG. 8. - Urnas «a mano" inciso-impresas. 

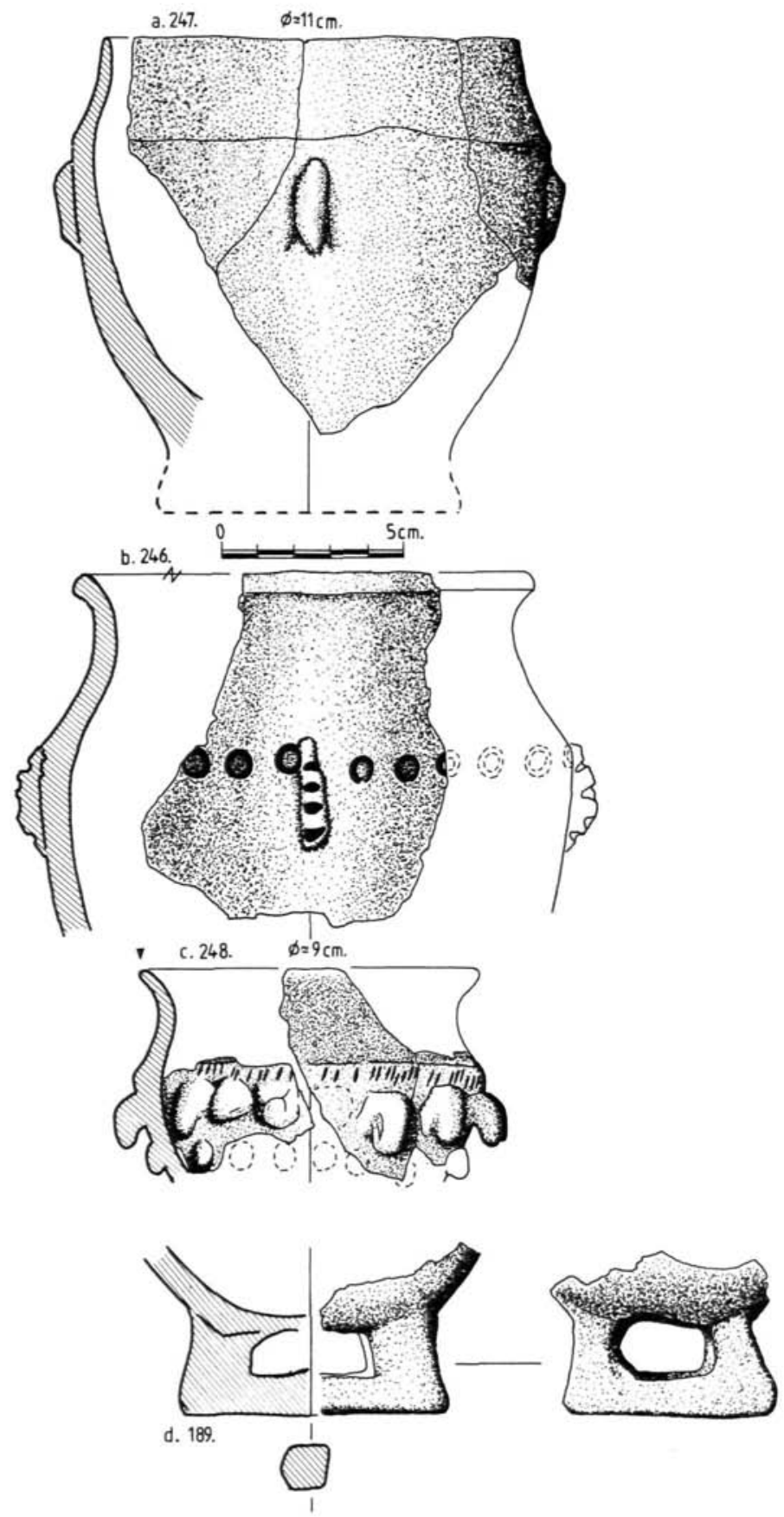

FIG. 9. - Urnas «a mano" con decoración aplicada, impresa e incisa. 

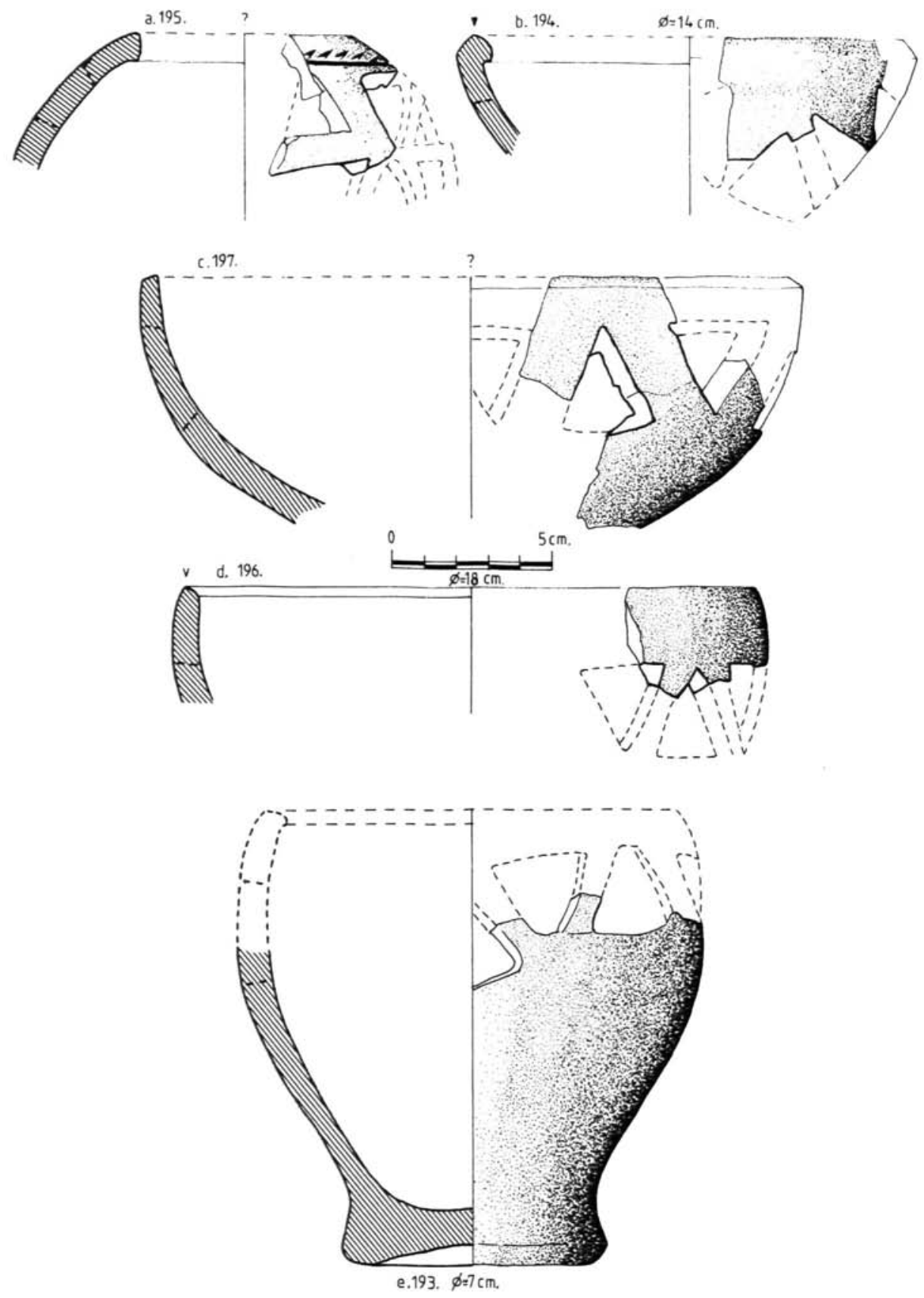

FIG. 10. - Recipientes calados «a mano». 

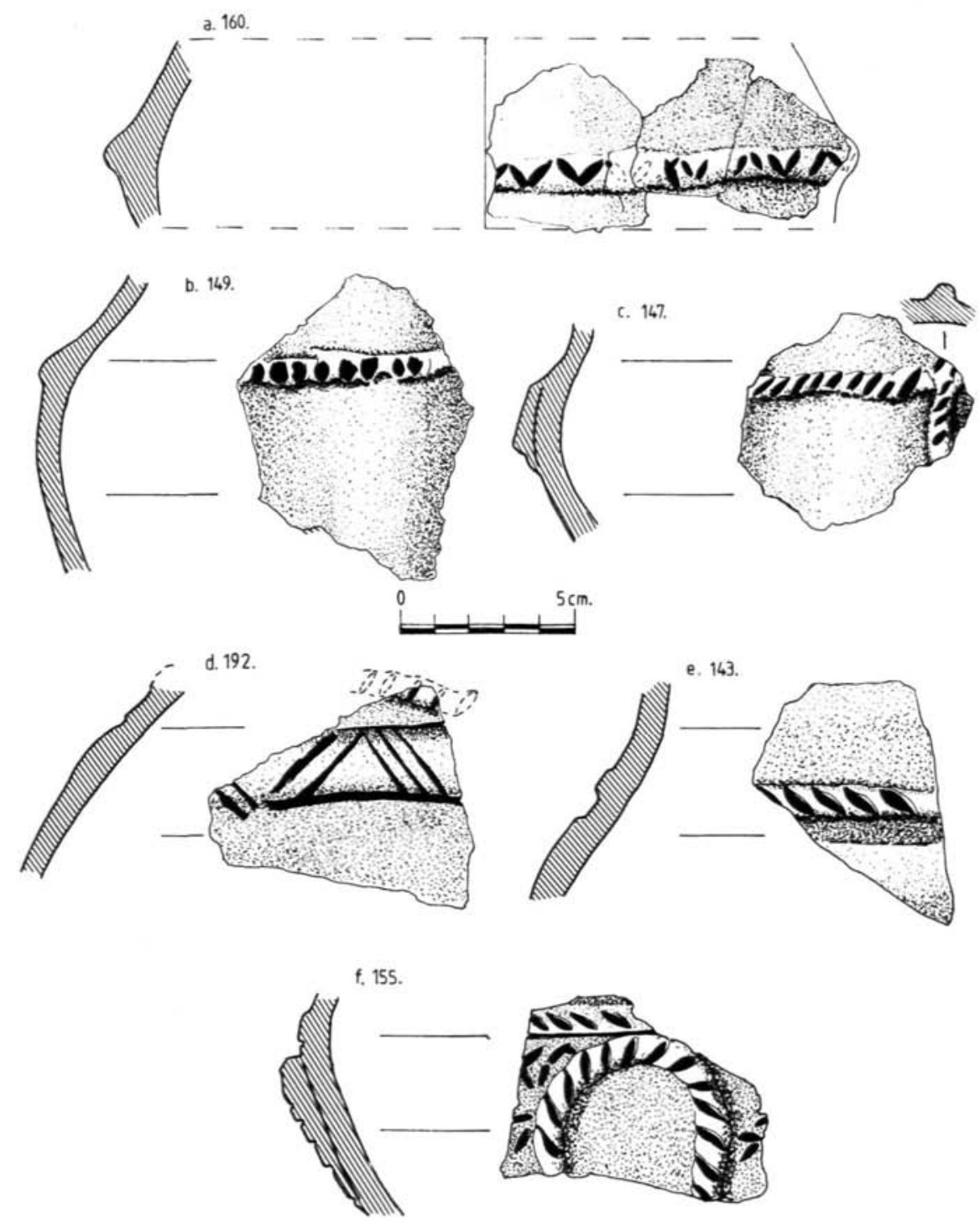

FIG. 11. - Fragmentos «a mano" con cordones aplicados, incisos e impresos. 

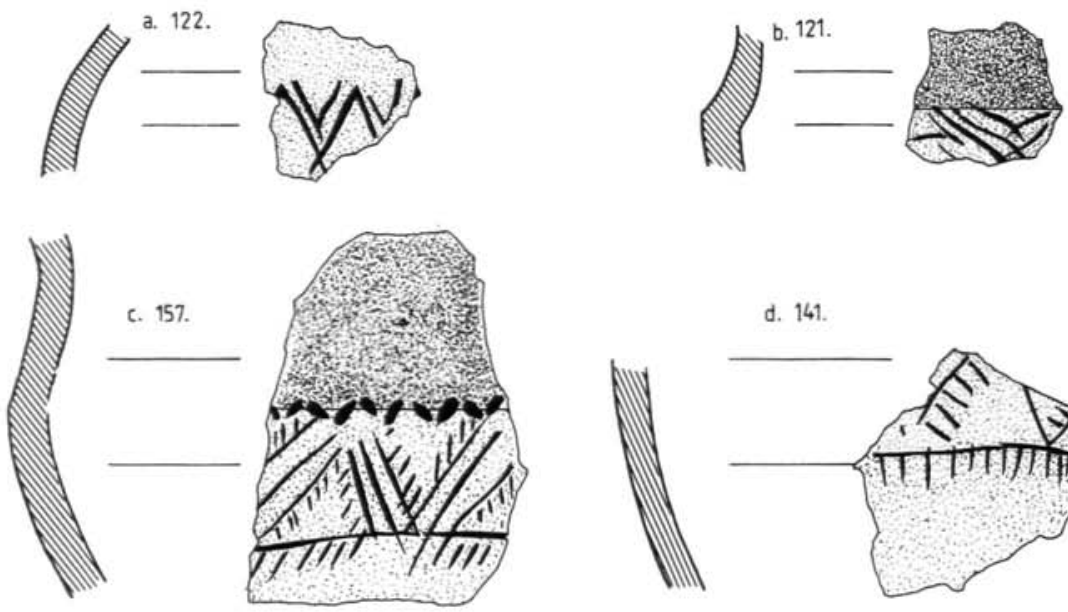

d. 141.
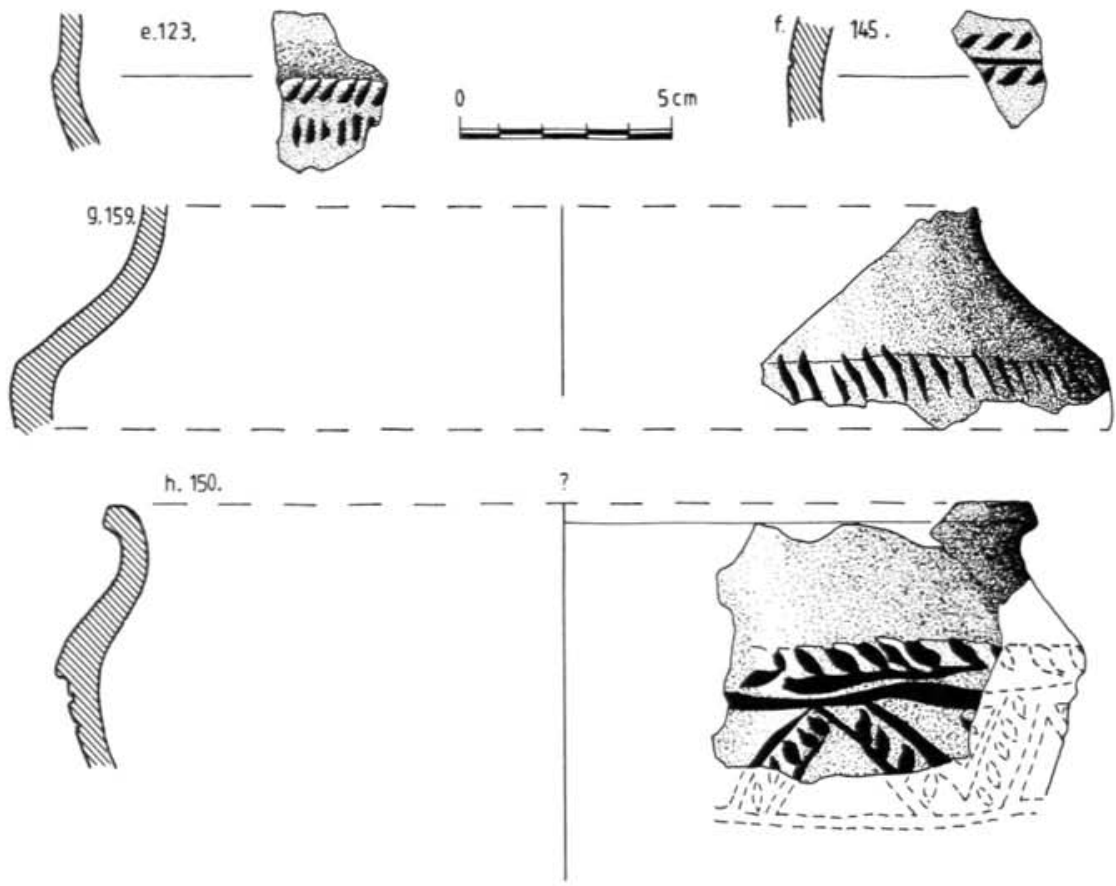

FIG. 12. - Fragmentos «a mano", decorados con motivos incisos. 

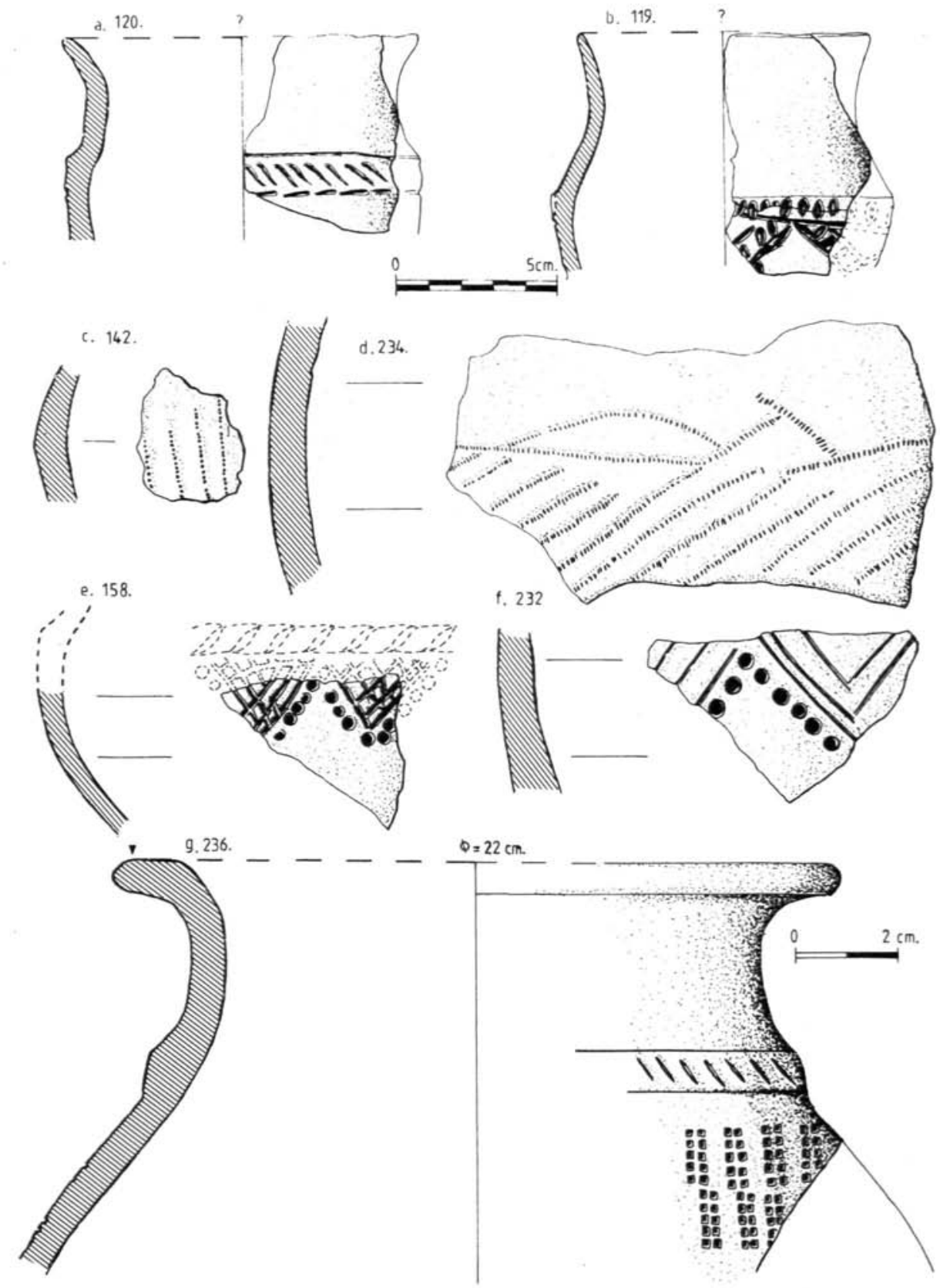

FIG. 13. - Fragmentos «a mano* con decoraciones incisas (a, b, e, f), impresa de púas de peine (c y d), impresas con extracción de pasta (e y f) y gris estampillada (g), este último, a torno. 
que hoy por hoy se encuentra poco estructurada debido al poco conocimiento que poseemos de la potohistoria extremeña (Almagro Gorbea, 1977; Maluquer, 1981, 1983 y 1986).

En su conjunto, tanto formas como motivos decorativos se encuentran bien representados entre las cerámicas a mano de la Baja Extremadura posiblemente durante la Segunda Edad del Hierro (Rodríguez Díaz, 1987, 650 y ss.), aunque nunca en tan elevado número y variedad de formas, con excepción de los recientes hallazgos procedentes del yacimiento de la Ermita de Belén (Zafra) y del castrejón de Capote, en su segunda campaña (Rodríguez Díaz, 1989 y Rodríguez Díaz et alii, e.p.). El dato que más caracteriza a estos conjuntos es la importante proporción de recipientes decorados que se registra entre la cerámica a mano, por otra parte de técnicas y formas muy homogéneas.

Además de ello, hemos de señalar que, en su contexto más amplio y dentro de este mismo horizonte cultural, los paralelos más directos y próximos de los hallazgos procedentes de Fregenal de la Sierra se encuentran en el denominado depósito votivo de Garvâo, cerca de Beja (Beirâo et alii, 1985, 45-135), y de forma más general en una serie de yacimientos localizados en torno a la cuenca media-baja del Guadiana, en la zona norte de Huelva y sobre todo en el Alentejo portugués, que en su conjunto constituyen la base del llamado Ferro II Continental, paralelo a Cogotas II (Gamito, 1981, 32-43; 1983, 65-78; Soares y Silva, 1979, 159-184; Silva, 1978, 117-132; Del Amo, 1978, 299-340). En este sentido estos materiales están también documentados durante este período en gran parte de la Meseta Norte española (Abásolo y Ruiz, 1979, 168-188; Abásolo, Ruiz y Pérez, 1983, 191-319; Fernández Gómez, 1986), donde además gozan de una tradición cultural que se remonta al Bronce Final y Primera Edad del Hierro.

II.2. Cerámicas toscas a torno: dentro de este grupo hemos incluido aquellas formas elaboradas con tonos oscuros - grisáceo o parduzco- escasamente decantadas, por cuanto contienen desgrasantes medios y gruesos, cocción oxidante o irregular y tosco acabado superficial. La mayor parte de los fragmentos proceden del poblado aunque no faltan en la posible necrópolis, asociadas a las producciones a mano (Fig. 14 b-h). Excepto algunos motivos estampillados, suelen ser lisas y sus formas remiten a grandes vasijas de almacén que se caracterizan por la diversidad de sus perfiles, algunos de los cuales llegan claramente a imitar modelos de ánforas de tradición ibero-púnica. Suelen presentar el borde engrosado y más o menos estrangulado, cuello con desigual desarrollo, cuerpo globular a veces con el hombro marcado y base plana. Pueden llevar asas anulares verticales. El diámetro de la boca oscila entre 25 y $50 \mathrm{~cm}$.

Junto a estas formas hay que señalar la existencia de vasijas de menor tamaño, de perfiles en "S", así como de un gran plato o fuente de casi $50 \mathrm{~cm}$. de diámetro.

Entre los fragmentos de mayor interés cabe destacar parte de una gran tapadera, con asa "de orejeta» (Fig. 14 b), de la que conocemos algunos paralelos dentro de los yacimientos cercanos del Ardila (La Martela y fundamentalmente Capote).

En líneas generales estas cerámicas poseen una escasa significación cronológica, aunque resultan muy frecuentes en contextos tardíos, próximos al contacto romano, en todos los yacimientos atribuibles a época prerromana en la Baja Extremadura. 
II.3. Cerámica a torno lisas y oxidadas: en un porcentaje cercano a $15 \%$, aparecen escasamente representadas respecto a lo conocido en otros yacimientos extremeños.

Como es sabido son cerámicas con unas características técnicas bastante homogéneas; pastas muy depuradas, color anaranjado o rojizo, buena cocción y cuidado tratamiento superficial. Sus formas resultan tremendamente variadas, aunque pueden ser incluidas en tres o cuatro grandes grupos: ánforas, grandes vasijas de almacén y formas abiertas y cerradas de menor tamaño (Figs. 14, 15, 16, 19 y 20).

Los fragmentos de ánforas son escasamente tres, procedentes del poblado y tipológicamente adscritos a formas iberopúnicas, ejemplares relacionados/evolucionados de las ánforas de borde trapezoidal realzado, borde grueso hacia el exterior y tendencia semicircular, con una cronología entre los siglos IV y III a. C. en el Cerro Macareno (Pelicer, 1978, 365 y ss.) Entre las formas de menor tamaño encontramos urnas de perfil globular y cuello desarrollado (Fig. 15 b-f), vasos de perfil en "S» (Fig. 15 a), algún tulipiforme y esencialmente cuencos/platos de diversos tipos. De estos últimos hemos recuperado un buen número, algunos casi completos, en la zona de la "necrópolis", asociados claramente a cerámicas a mano, lisas y decoradas. En su mayoría responden al tipo de borde normal, cuerpo semiesférico y base plana o ligeramente cóncava, aunque también resultan frecuentes los de borde recto y perfil semiesférico o recto (Fig. 16). El diámetro medio de estas piezas gira en torno a los $18 \mathrm{cms}$. y frecuentemente presentan dos pequeñas perforaciones como posibles elementos de suspensión, muy próximos entre sí, bajo el borde. Iguales formas y asociación se documentaron en Garvâo.

Nuevamente son materiales de poco valor cronológico, por cuanto son producciones comunes, inspiradas en los presupuestos culturales de fabricación de los productos oxidados, lisos y pintados, que dominaron en valle de Guadalquivir entre los siglos V/VI a. C. y la romanización (Pellicer, Escacena y Bendala, 1983, 81 y ss.). Sin embargo a partir del análisis tipológico realizado de los materiales oxidados procedentes del poblado de Los Castillejos de Fuente de Cantos (Fernández Corrales, Sauceda y Rodríguez, 1988, 69-88) y de la asociación de cuencos oxidados y cerámica a mano decorada, idéntica a Garvâo (Beirâo et alii, 1985), fecha de la segunda mitad del siglo IV y primera del III a. C. parece aceptable.

II.4. Cerámicas pintadas: Dentro de este grupo de oxidadas, hemos de referirnos aparte, por su importancia, a un pequeño conjunto de materiales pintados. Salvo dos fragmentos, el resto procede del área de la "necrópolis", donde aparecen claramente asociadas al resto de los tipos analizados.

Son principalmente recipientes globulares, de tamaño considerable $(18-20 \mathrm{~cm}$. de diámetro en el labio), perfil ovoide o globular, borde normal exvasado y cuello más o menos desarrollado. No faltan baquetones que realzan la unión del cuello con el cuerpo (Figs. 19 y 20).

Los motivos pintados se reducen a asociaciones de bandas paralelas de distinto grosor, si bien nuevas prospecciones nos han proporcionado fragmentos decorados con líneas sinuosas y semicírculos concéntricos. La calidad de la pintura es variable y el color más utilizado es el rojo vinoso, en ocasiones asociado al negro. 

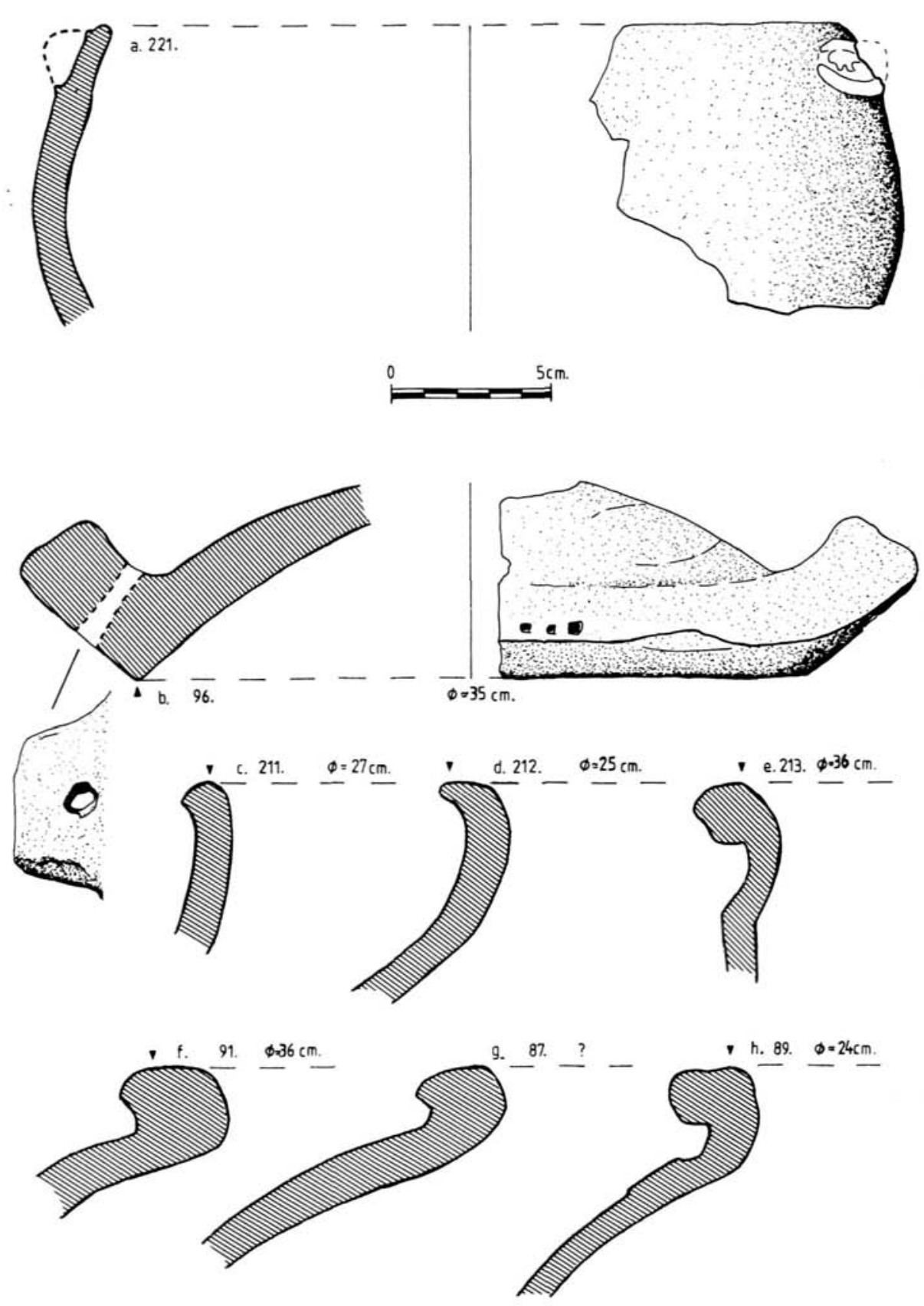

FIG. 14. - Fragmentos de cerámicas toscas, a mano (a) y torno (b y h). Principales perfiles de vasijas de almacén $\mathrm{y}$ ánfora «ibero-púnicas” (c y h). 

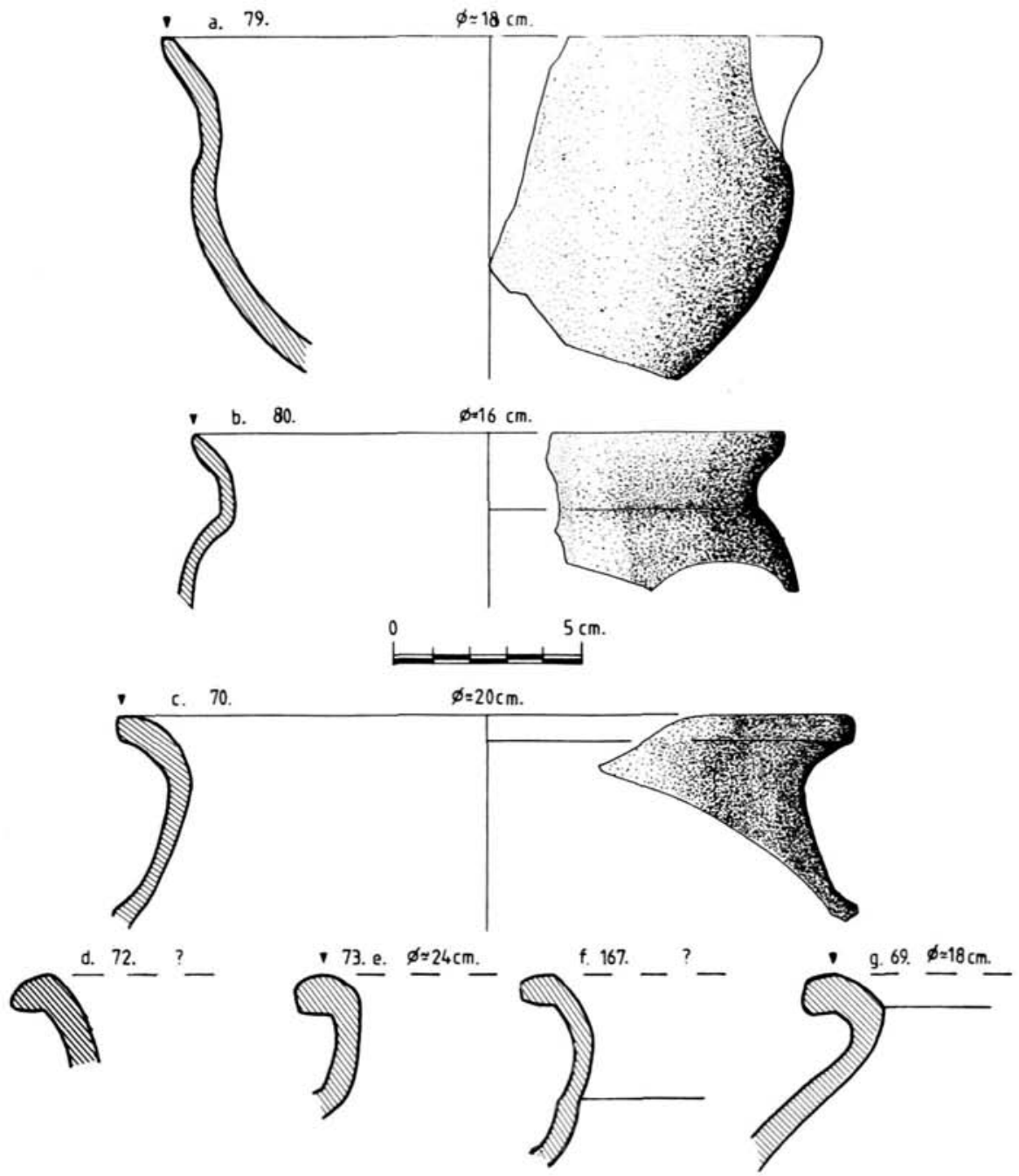

FIG. 15. - Vasijas «oxidadas" y lisas, a torno. 

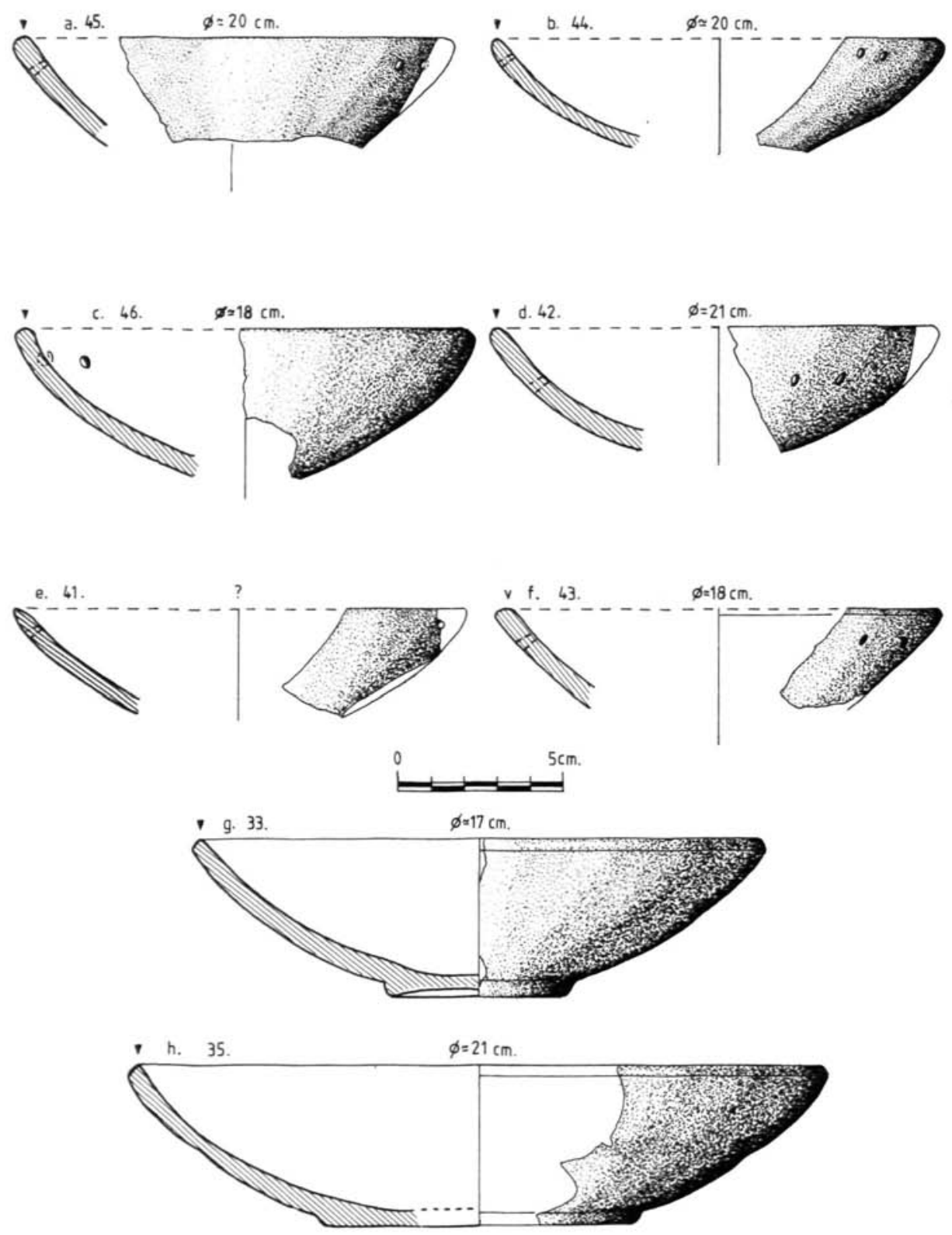

FIG. 16. - Cuencos «oxidados" y lisos, a torno. 

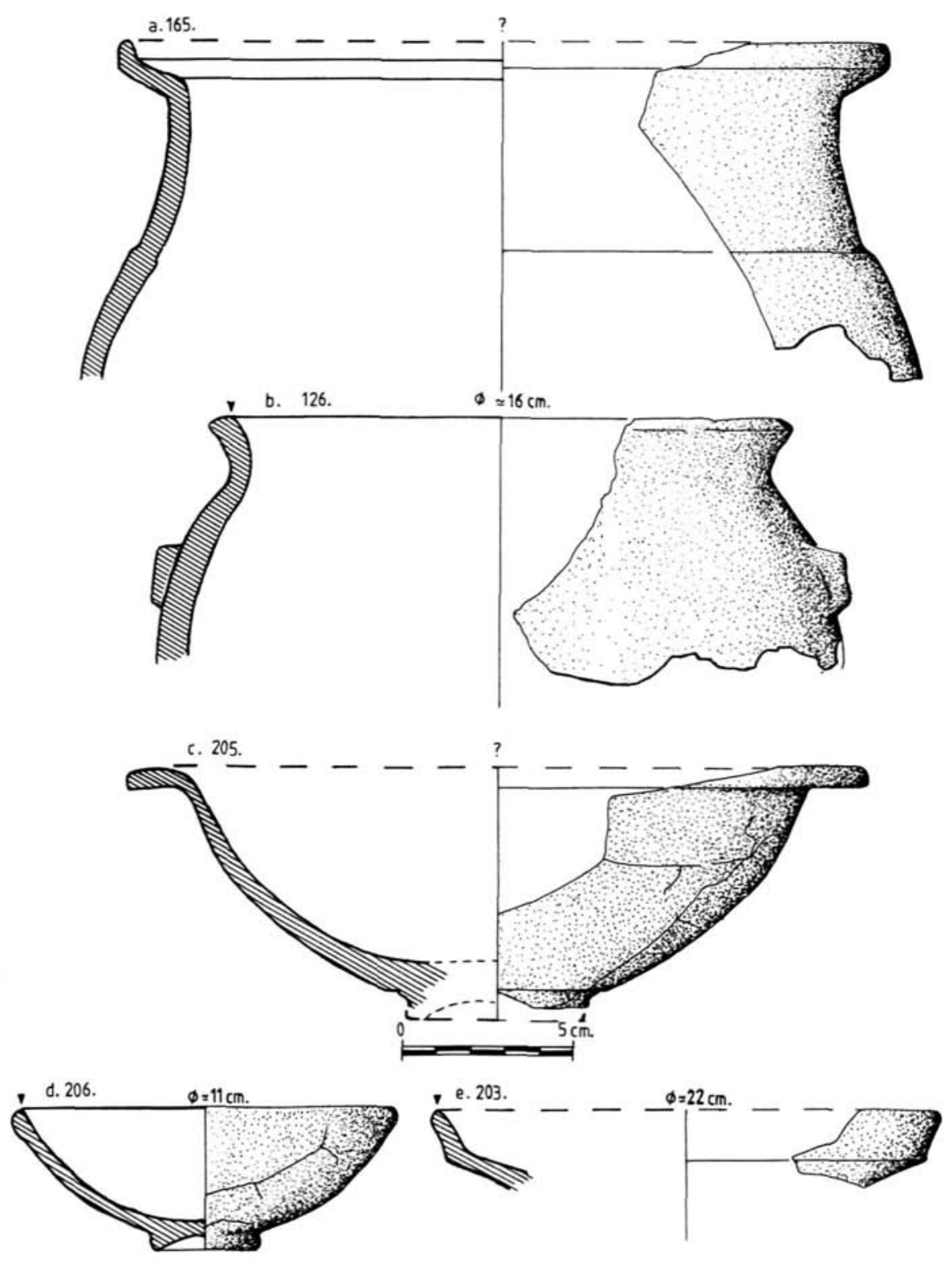

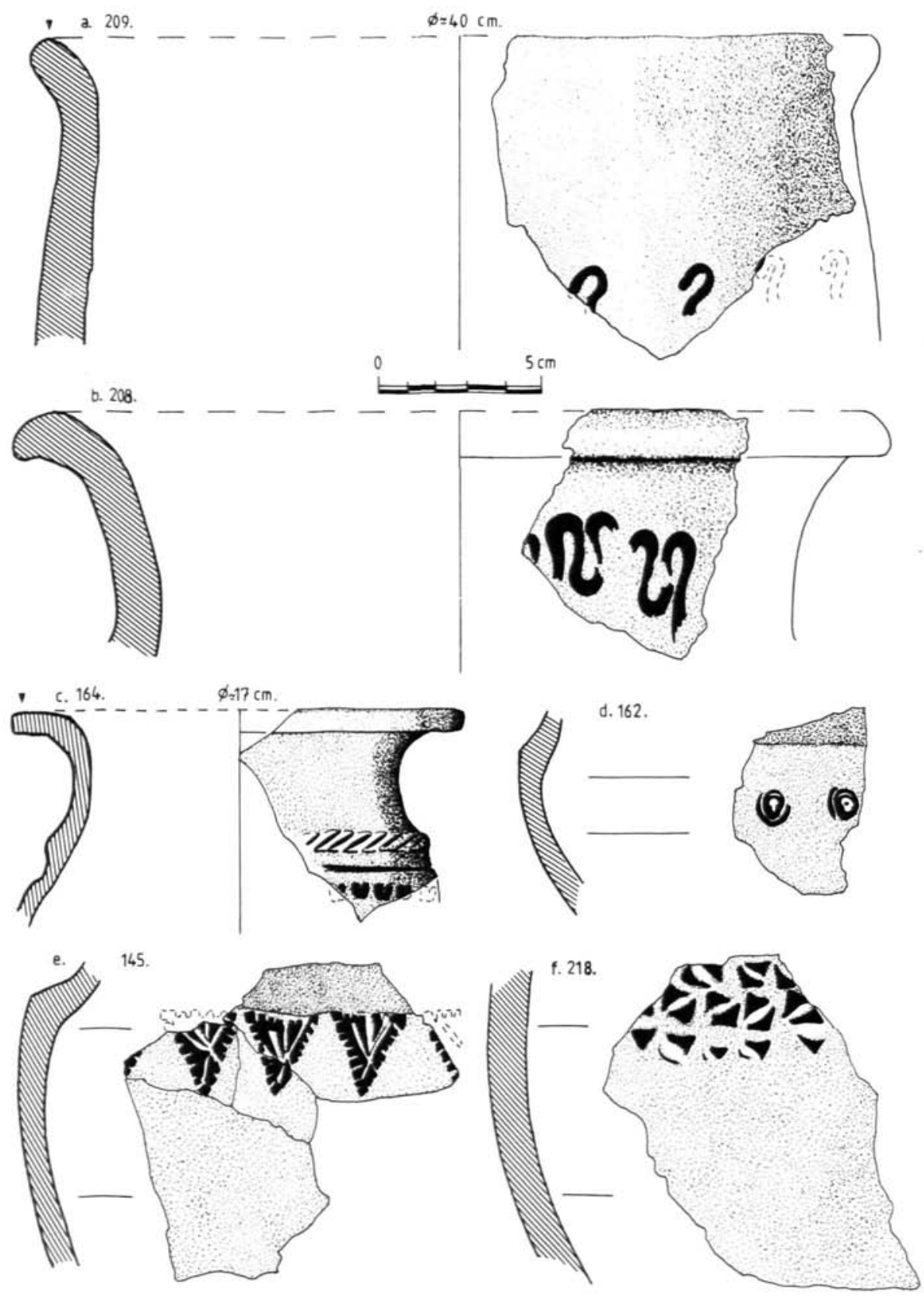

FIG. I8. - Cerimicas estampilladas, -a mano- (d y e), toscas a torno (a, b y $f$ ) y gris cstampillada (c). 

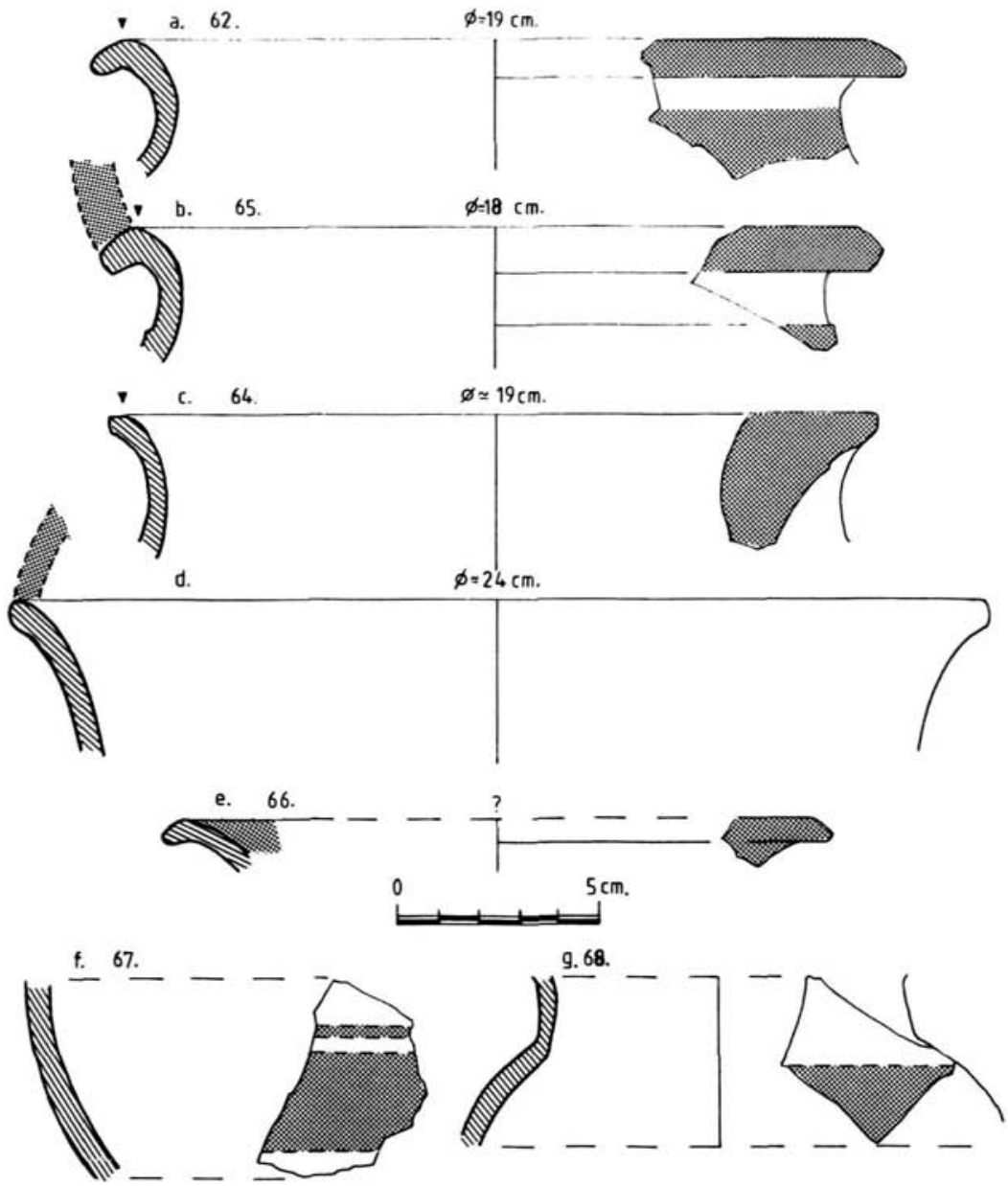

FIG. 19. - Vasijas «oxidadas" y pintadas en rojo vinoso. 
En este grupo cabe destacar un fragmento de galbo de cocción reductora y pasta compacta, que presenta, al exterior, una franja de densa pintura amarilla, contorneada por encima y debajo, por sendas bandas rojas y decorada por otra línea, ondulante del mismo color, cruzada por trazos oblícuos en negro (Fig. 20 c.) La adscripción cultural de esta pieza, dado el amplio contexto de procedencia, es un tanto compleja aunque las escasas cerámicas romanas que también se hallaron en la "necrópolis" pueden ayudar a considerarla dentro de un contexto próximo o coetáneo a la romanización, en ambientes del Occidente Peninsular (Alarcao e Mountinho, 1976).

En conjunto estas cerámicas muestran los motivos geométricos lineales tan ampliamente documentados en todos los yacimientos protohistóricos de sur y centro peninsular (López Palomo, 1981, 33-187) entre los siglos V/IV a. C. y la romanización. Por ello resulta innecesario referirnos puntualmente a cada uno de ellos.

II.5. Cerámicas grises: nuevamente una escasa presencia, esta vez por debajo del $10 \%$ de la muestra, caracteriza este grupo en el Cantamento respecto a los poblados excavados vecinos de Capote y La Matela, donde es muy abundante. Sin duda este debe ponerse en relación con la procedencia de la mayoría de las piezas, de la supuesta necrópolis, en la que las producciones a mano son mayoritarias.

En líneas generales, están realizadas con pastas muy depuradas - desgrasantes micáceosde tonos entre el gris claro y el negro, cocción reductora y alisado superficial, a veces pulido $e$ incluso bruñido.

Tipológicamente estas cerámicas remiten a formas cerradas u abiertas de tamaño medio. Entre las primeras destacan las urnas, de perfil globular y borde exvasado de sección cuadrada, y los vaso de perfil en "S" (Fig. 13 g; 17 a y b; 18 c.). Por su parte, las formas abiertas se concretan en cuencos y platos semiesféricos de borde normal y base cóncava con umbo ligeramente marcado; platos de borde saliente, cuerpo curvo o carenado y base cóncava con umbo y por último una serie de páteras y cazuelas de borde redondeado y cuerpo con carena a media altura, más o menos marcada (Fig. 17 c, d y e). Son formas de larga tradición en el SO. donde habían alcanzado su auge en los siglos VIII y V a. C. (Belén, 1976, 353-388; Belén, Fernández Miranda y Garrido, 1977; Almagro Gorbea, 1977, 394 y ss.) aunque sin duda se mantienen hasta la romanización (Pellicer, 1979-1983). En la Baja Extremadura así parece confirmarse en yacimientos como la Sierra de la Martela, Capote, El Coto, Nertóbriga, Hornachuelos, Belén o Los Castillejos de Fuente de Cantos (Enríquez y Rodríguez, 1988, 125 y ss.; Berrocal, 1988-a, 59-61; de La Barrera et alii, e.p.; Rodríguez Díaz, 1987; Fernández Corrales, Sauceda y Rodríguez, 1988), en los que además se constatan en contextos de los siglos III y IV a. C.

Sus decoraciones suelen ser estampillads, con motivos dispuestos en una o más bandas horizontales a la altura del hombro. En ocasiones van acompañados de cordones, ungulados o inciso punzados, que marcan el inicio del cuello y entre sus motivos destacan los «escutiformes" rectangulares o triangulares, reticulados así como los círculos, concéntricos o no (Figs. $13 \mathrm{~g} ; 18 \mathrm{c}, \mathrm{d}$ y f).

El comportamiento de este tipo cerámico, cuya valoración final está ligada obligatoriamente a la estimación de la cerámica gris estampillada, resulta tremendamente desigual en 
los yacimientos referidos, registrándose mayores porcentajes en los localizados en el suroeste de la provincia pacense, cercano al Alentejo (Arnaud e Gamito, 1974-1977, 165-200) y Huelva, como se confirma en los de Higuera la Real (Berrocal, 1988-a, 59) y Jeréz de los Caballeros (según información oral que agradecemos a D. ${ }^{a}$ M. Jesús Carrasco).

II.6. Cerámicas estampilladas: dentro de la unidad que comporta una misma técnica decorativa hemos de significar que hay una marcada diferencia de fabricación que, dentro del muestreo estudiado, permite distinguir dos subgrupos o variantes: las cerámicas toscas, realizadas a torno lento y posiblemente a mano, con pastas poco depuradas, pardo obscuras, cocción alterna y alisado superficial (Fig. $18 \mathrm{f}$ ), propias de contenedores de tamaño notable, como los bien conocidos en Garvâo (Beirâo et alii, 1985, 73). El otro subgrupo, de cerámicas grises estampilladas responden a urnas menores, de perfiles globulares, con la separación entre cuerpo y cuello, marcado con un suave baquetón, a veces inciso (Fig. $13 \mathrm{~g} \mathrm{y} 18 \mathrm{c}$ ). El tamaño de las estampillas, menor en la segunda variante, contribuye a remarcar esta diferenciación. Como el anterior, sus mejores paralelos se encuentran en el Alentejo Portugués y el Oeste de Extremadura (Arnaud e Gamito, 1974-1977; Berrocal, 1988, 271-273; Rodríguez Díaz, 1987, 777 y ss.).

II.7. Las fusayolas recuperadas alcanzan el número de cinco. A ellas hay que sumar dos "pondera", rectangulares, de cocción irregular y tratamiento grosero, con un orificio cada uno y uno de ellos con la cara superior decoradas con incisiones corridas fuertes.

Las fusayolas son fundamentalmente de perfil bitroncocónico (tipos E1 y D1 de Castro Curel, 1980, 138), registrándose una cónica (tipo C1). Van decoradas en su mitad superior con incisiones punzadas e impresiones a peine. Son piezas sobradamente conocidas durante la Edad del Hierro en nuestra región y en general en todo el ámbito peninsular (Castro, 1980, 138 y ss.).

II.8. Cerámicas romanas, aunque en un porcentaje cercano a $10 \%$, la presencia romana en el Cantamento queda constatada en casi una treintena de materiales diversos, que a grandes rasgos llevan al siglo I d. C.

Básicamente se reducen a vasos de Terra Sigillata, vidrio, paredes finas y cerámicas comunes que en algunos casos podrían remontarse a los últimos momentos de la República.

II.9. La coroplástica está representada por un pequeño fragmento, procedente de la posible necrópolis, consistente en un par de manos entrelazadas, partiendo de dos brazos unidos, de forma que configuran un círculo (Fig. 22 e). La pasta es obscura y grosera, con cocción irregular.

Desgraciadamente el reducido tamaño del fragmento impide conocer si pertenecía a una figura exenta o bien, en vista de la caprichosa posición de las manos, a un elemento antropomórfico adjunto a un recipiente cerámico, de manera que entre las manos pasaría una cuerda sustentente. Piezas similares se hallaron en Garvâo y se ponen en relación con grandes recipientes metálicos etruscos y de La Ténè (Beirâo et alii, 1985, 81 y ss.).

II.10. El material metálico está compuesto por dos puntas de flecha o jabalina de las que una, de bronce, fue hallada en las cercanías del poblado (Fig. 22 a). Además hay que 

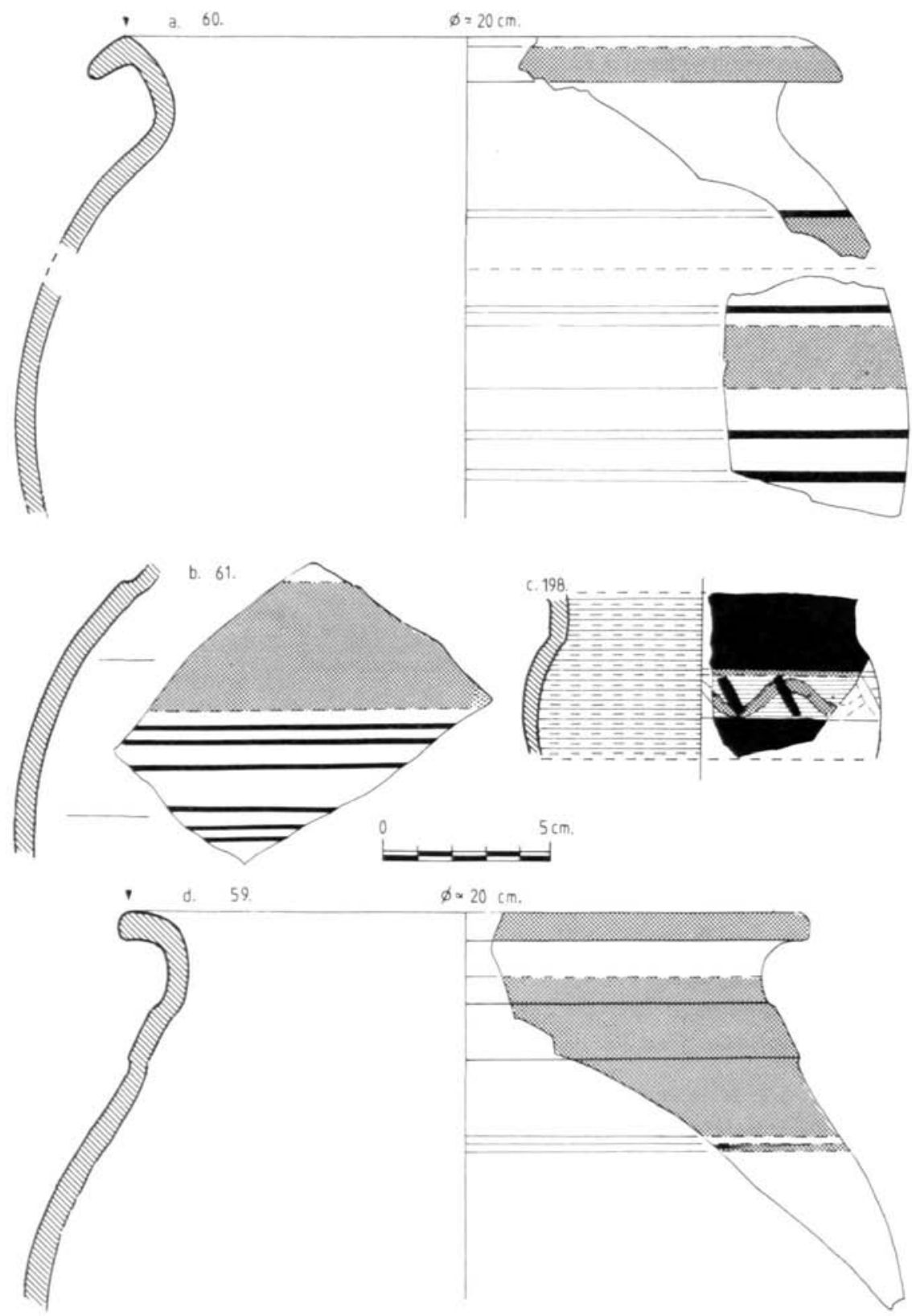

FIG. 20. - Vasijas -oxidadas- y pintadas en rojo y negro. La pieza c. 198 muestra una banda amarilla flanqueada por dos rojas, estrechas y con otra, ondulante, de este color, cruzada con trazos negros. La superficie interior está engo. bada en narania y la exterior muestra el color negro de la pasta. 

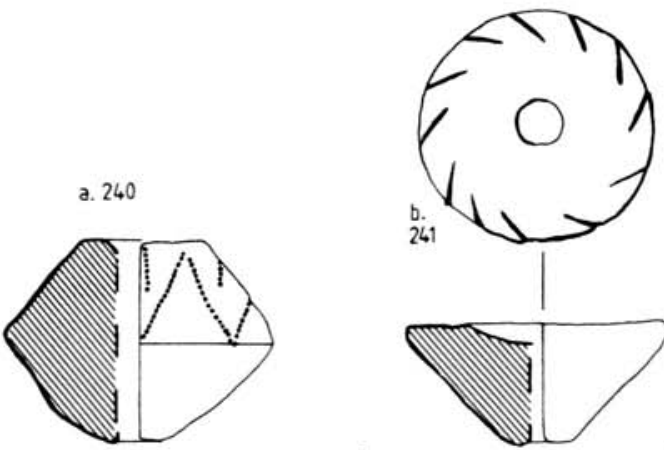

c. 242
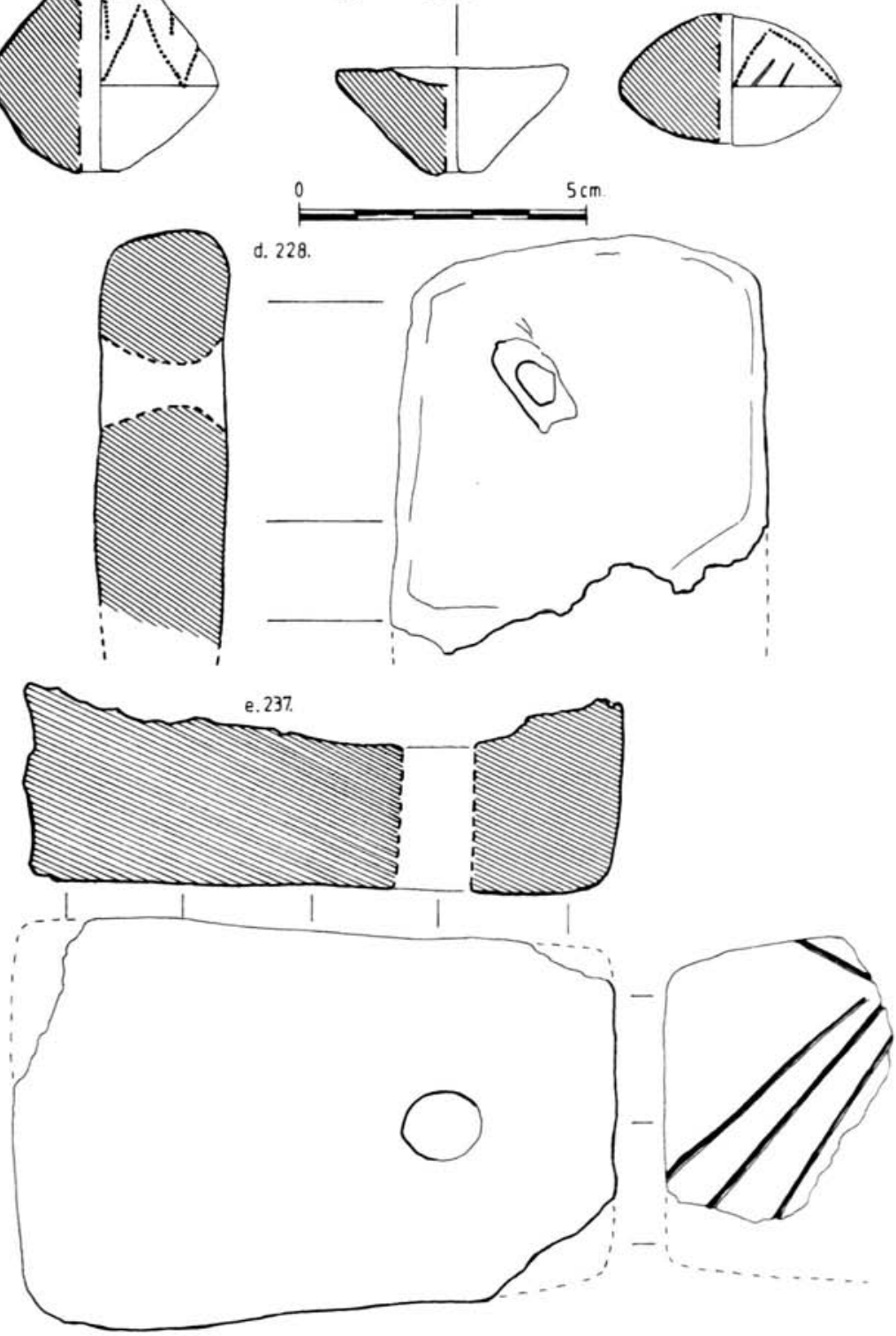

FIG. 21. - Fusayolas y pondera. 
anotar dos fragmentos de regatones de lanza, de perfil cónico, como la primera pieza, procedentes de la necrópolis (Fig. 22 b y c).

Estos tipos de armas resultan bastante frecuentes, documentados en los dos niveles de ocupación de Los Castillejos de Fuente de Cantos, entre los siglos IV y I a. C. y en superficie en el también poblado del Castillo de Bienvenida (Rodríguez Díaz, 1987, 843 y ss.).

Los regatones están presentes en numerosos yacimientos de esta época, como es el caso de Azaila, Castillejo de la Romana, La Coronilla de Aragón o en algunas tumbas de La Osera (Schüle, 1969; Beltrán Lloris, 1976; 1979, 255-300; Cerdeño y García Huertas, 1982; Cabré, Cabré de Morán y Molinero, 1950).

\section{Valoración final}

A pesar de contar con un muestreo de materiales amplio y variado, es lógico imaginar que su valoración está necesariamente supeditada la realización de trabajos arqueológicos en este lugar que aporten nuevos datos y arrojen luz sobre su contexto real y sobre todo, su cronología.

En este sentido y en base a los resultados obtenidos en los trabajos desarrollados en nuestra región y en zonas más o menos próximas durante los últimos años, tan sólo podemos señalar que los hallazgos procedentes del Cantamento de la Pepina se integran en el horizonte cultural prerromano cuyos límites cronológicos, hoy por hoy, parecen situarse desde el siglo IV a la época imperial romana. Este imprecisión cronológica viene motivada en gran parte por la ausencia de materiales arqueológicos que proporcionen dataciones firmes y la carencia de estratigrafías amplias que nos aproximen al conocimiento de la protohistoria extremeña.

A pesar de todo, estos nuevos hallazgos extremeños vienen a confirmar una vez más que nos encontramos ante una cultura muy personalizada y definida, que básicamente parece estar configurada por un subtrato de raigambre meseteña, evidenciado particularmente en las cerámicas a mano decoradas y a torno toscas estampilladas, muy matizado por los influjos culturales del Oeste y Sur peninsular, como reflejan las producciones cerámicas a torno en general. A escala regional, dicho horizonte se detecta igualmente en diversos yacimientos de la propia provincia de Badajoz y en Centro-Sur portugués, justamente en la zona identificada por los escritores clásicos como habitada por pueblos "Célticos", y en la cuenca del Ardila, más concretamente, como la "Beturia de los Célticos" (Berrocal, 1988, cap. III). 

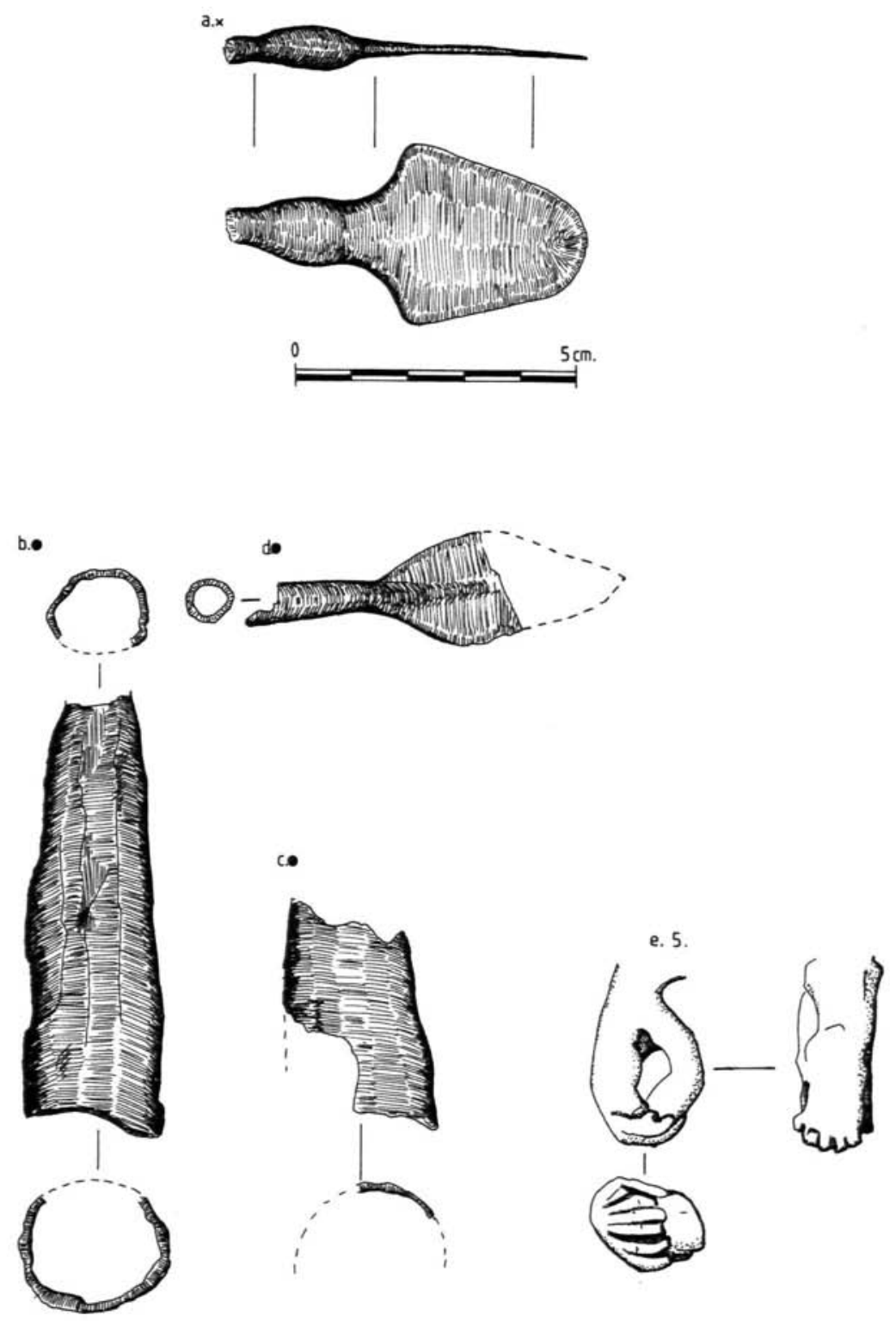

FIG. 22. - Material de hierro y bronce (a). La pieza e. 5 es un fragmento de terracota de tosca factura y pasta obscura. 


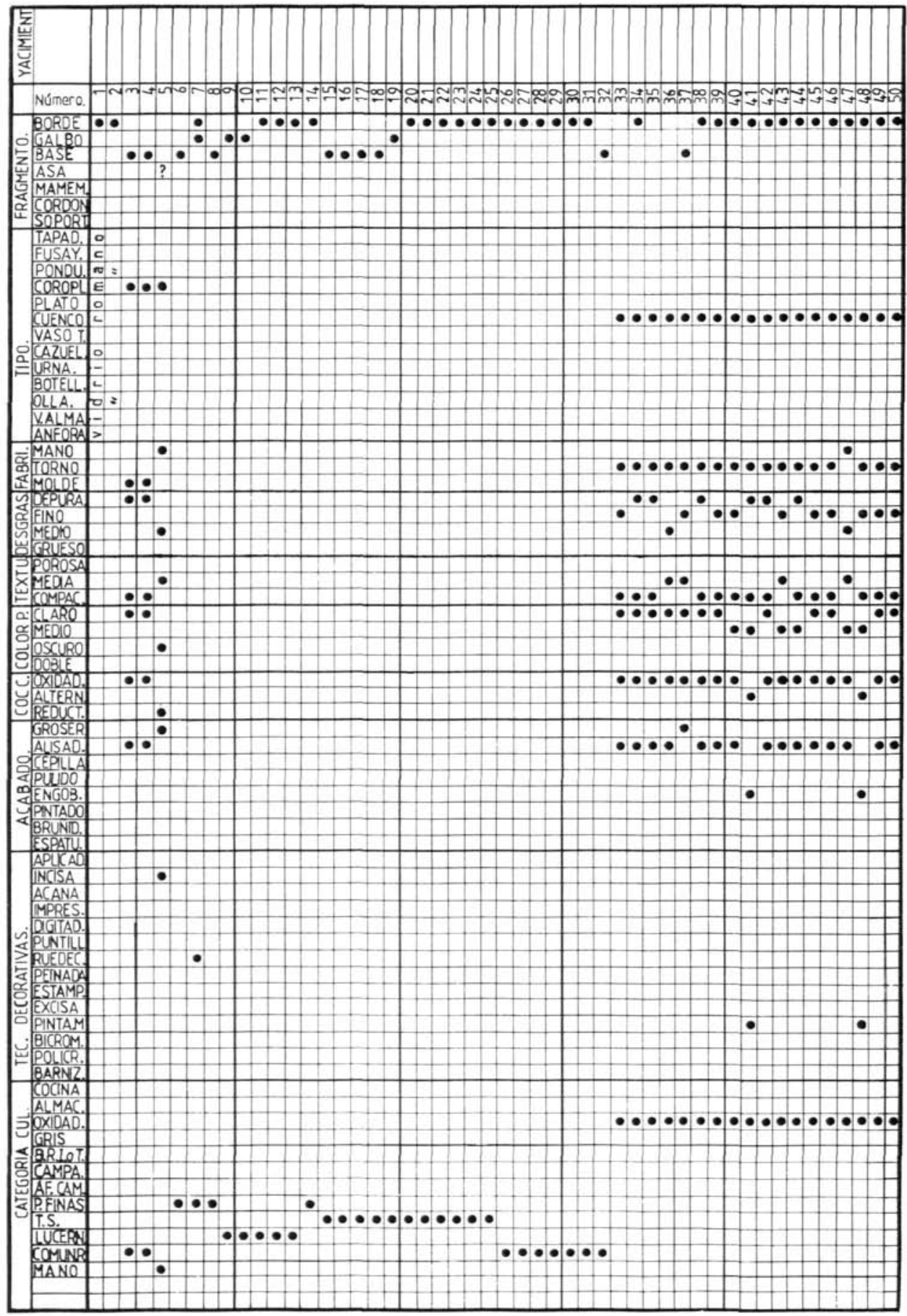




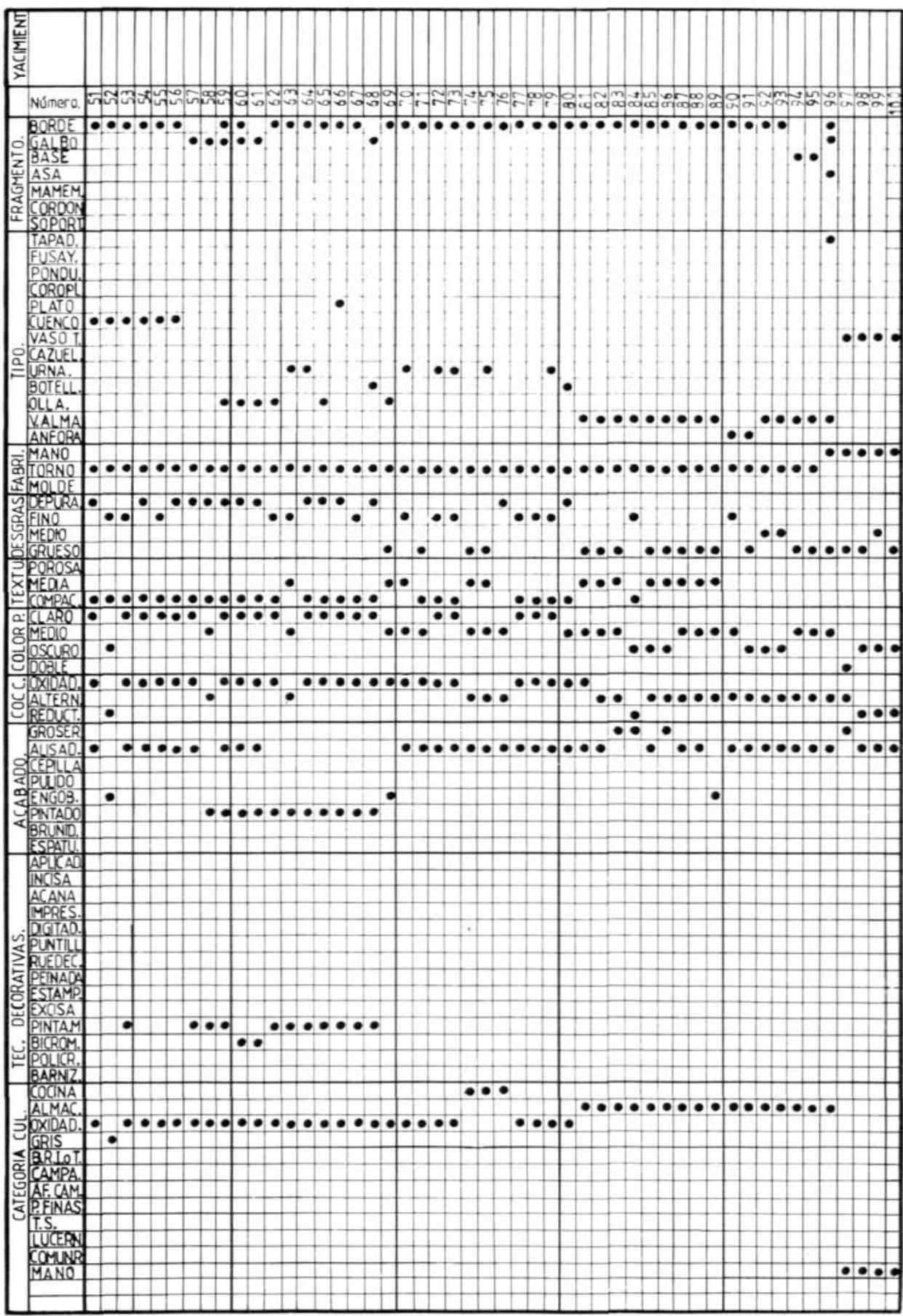




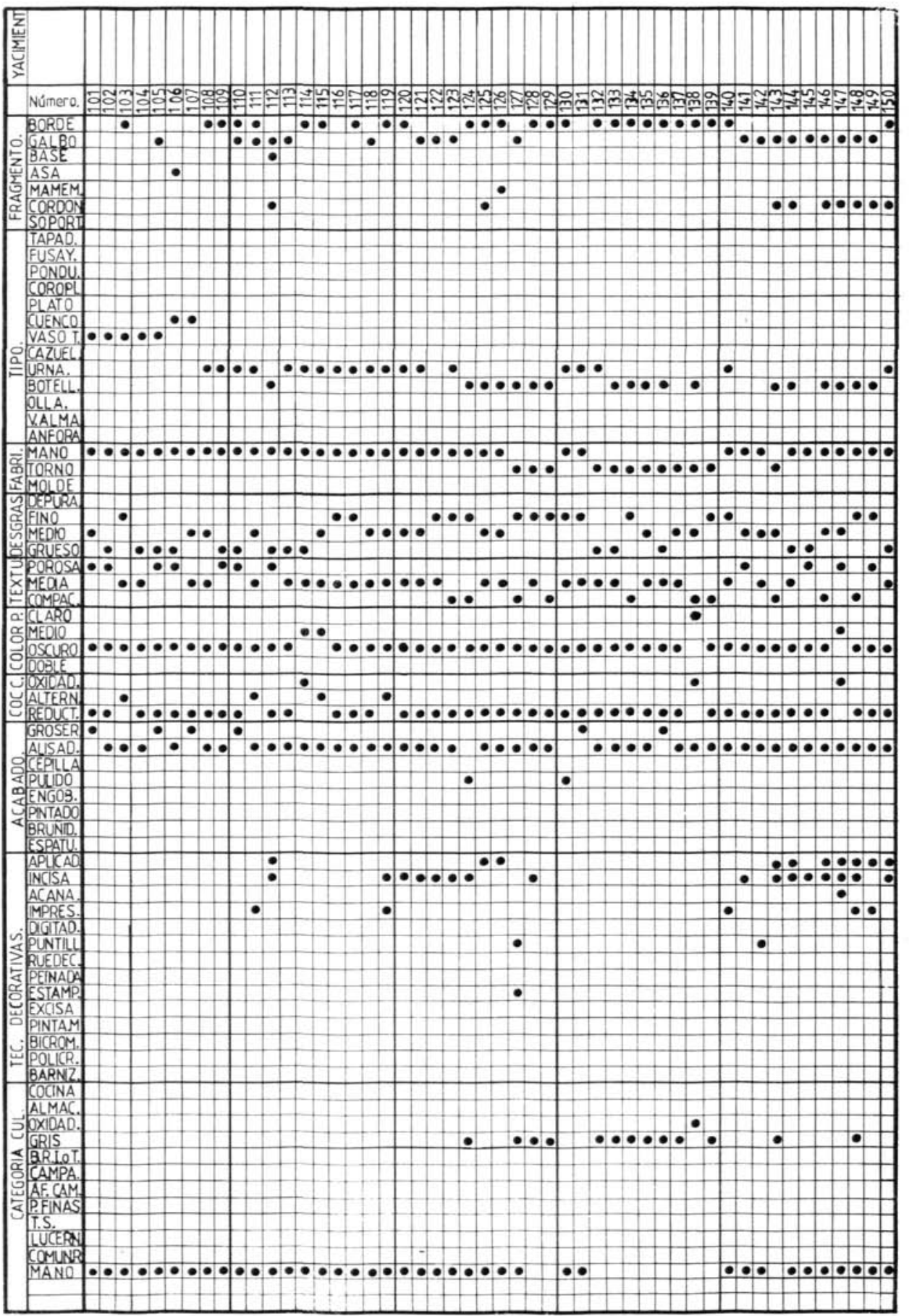




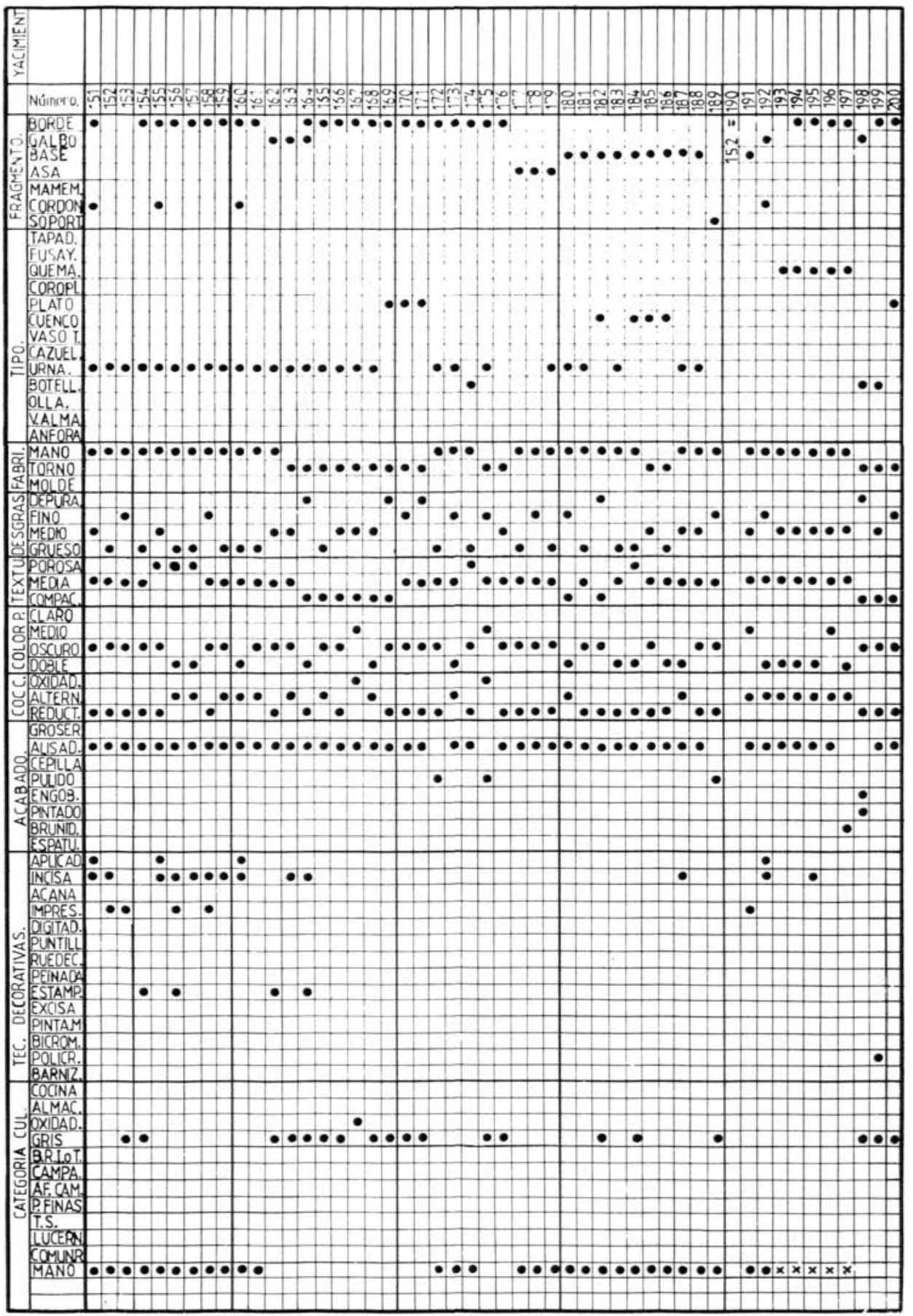




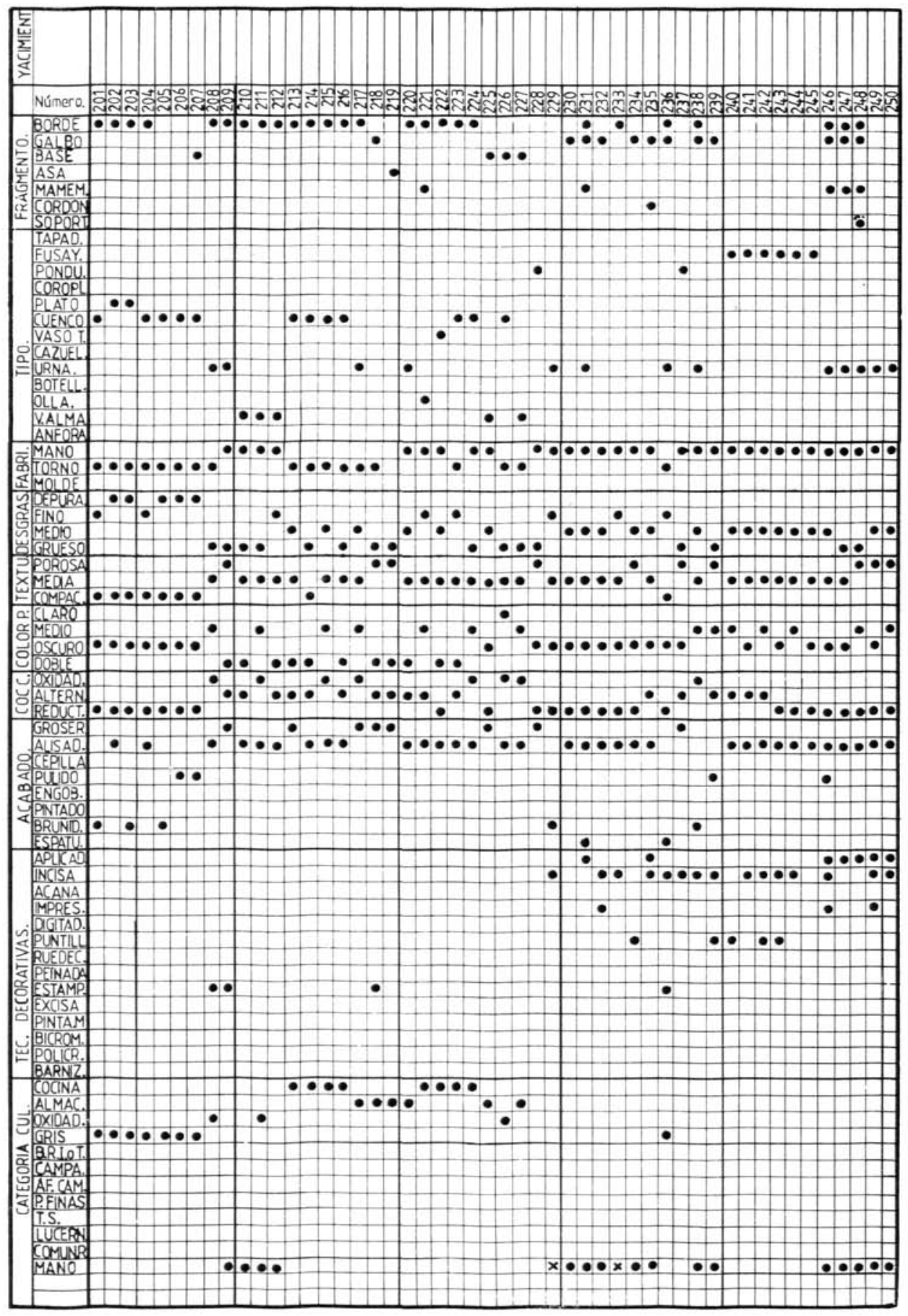




\section{BIBLIOGRAFIA}

ABÁSOlO, J. A. y RUIZ, I. (1979): «Un conjunto arqueológico de Ubierna. Contribución al estudio de la Edad del Hierro en la Meseta Norte». Bol. Seminario Arte y Arqueologia, XLV, 168-188.

AbÁsolo, J. A.; Ruiz, I. y PÉReZ, F. (1983): "Castrojeriz, I. El vertedero de la Colegiata". NAH, 17, 191-319.

Alarcao, J. y Mountinho, A. (1976): «Cerámiques peintes». A propos des Cerámiques de Coninbriga, París.

Almagro GorbeA, M. (1977): El Bronce Final y el Periodo Orientalizante en Extremadura. BPH, XIV, Madrid.

ARNAUD, J. M. y Gamito, T. J. (1974-77): “Cerâmicas estampilhadas da Idade do Ferro do sul de Portugal. I. Cabeça de Vaiamonte-Monforte». O. Arq. P., VII-IX, 165-200.

Beirao, C. De M., Silva, C. T. DA, M. V. y Varela, R. V. (1985): «Depósito votivo da II Idade do Fero de Garvâo. Noticia da primera campanha de escavaçoes”. O. Arq. P., 3, Ser. IV, 45-135.

BELÉN DEAMOS, M. (1976): "Estudio y tipología de la cerámica gris en la provincia de Huelva». RABM, LXXIX, 353-388.

Belén, M., Fernández Miranda, M. y Garrido, J. (1977): "Los orígenes de Huelva. Excavaciones en los cabezos de San Pedro y La Esperanza: Huelva Arqueológica III.

Beltrán Lloris, M. (1976): Arqueología e bistoria de las ciudades del Cabezo de Alcalá de Azaila (Teruel). Zaragoza.

- (1979): Poblado ibérico de El Castillejo de la Romana (La Puebla de Hijar, Turuel). EAE, 103.

Berrocal RANGel, L. (1988): La Segunda Edad del Hierro en la Cuenca del Ardila. Aproximación arqueológica al concepto histórico de la Beturia de los Celticos. Memoria de Licenciatura. Universidad Autónoma de Madrid.

- (1988-a): Excavaciones en Capote (Beturia Céltica), I. Serie Nertobriguense, 1. 84 pp.

- (1989): «Cerámicas a mano de una necróplis nertobriguense (Frenegal de la Sierra, Badajoz)». Actas II Coloquio sobre los Celtiberas (Daroca, 1988).

CABre, J., CABre de MORÁN, E., y MOlinero, A. (1950): «El castro y la necrópolis del Hierro céltico de Chamartín de la Sierra (Avila)m. Acta Arqueológica Hispana, V.

Castro Curel, Z. (1980): "Fusayolas ibéricas. Antecedentes y empleo». Cypsela, III, 138 y ss.

Cerdeño, M. L. y García Huertas, R. (1982): "Avance de la estratigrafía protohistórica de La Coronilla (Molina de Aragón, Guadalajara)». NAH, 14, 255-300.

De la Barrera, J. L., Velázquez, A. Oyola, A., y Berrocal, L., e.p.: Nertobriga Concordia Iulia, I. Serie Nertobriguense, 2.

Del AMO, M. (1978): «El Castañuelo. Un poblado céltico en la provincia de Huelva». Huelva Arqueológica, IV, 299-340.

EnRíquez Navascues, J. J., y Rodríguez Díaz, A. (1988): "Campaña de urgencia en la Sierra de la Martela (Segura de León, Badajoz)». Extremadura Arqueológica, I., 113-128.

Fernández Corrales, J. M., Sauceda, M. I. y Rodríguez, A. (1988): «Los poblados calcolítico y prerromano de Los Castillejos de Fuente de Cantos (Badajoz)m, Extremadura Arqueológica, I., 69-88.

FERNÁNDEZ GOMEZ, F. (1986): Excavaciones arquelógicas en el Raso de Candeleda, I y II. Avila.

Gamito, T. J. (1981): "A propósito do castro de Segovia (Elvas). Residencia a Roma no Sudoeste peninsular". Historia, 29, 32-43.

- (1983): "A Idade do Ferro no sul de Portugal. Problemas e perspectivas". Rev. Arqueologia, 6, 65-78, Oporto. 
LÓPez Palomo, L. A. (1981): Albonoz. (Excavaciones de 1973 a 1978). NAH, 11, 33-188.

MALUQUeR DE MOTES, J. (1981, 1983 y 1986): El santuario protobistórico de Zalamea de la Serena, Badajoz, I, II y III, PIP, IV, V y XVI, Barcelona.

Pellicer CATALÁN, M. (1978): «Tipología y cronología de las ánforas prerromanas del Guadalquivir, según el Cerro Macareno (Sevilla)». Habis, 9, 365 y ss.

- (1979-1983): «Las cerámicas del mundo fenicio en el Bajo Guadalquivir. Evolución y cronología según el Cerro Macarenom. International Symposium Phonizische Expansión im Westlichen Mittelmeerraum (Kolh, 1979).

Pellicer, M., Escacena, J. L. y Bendala, M. (1983): El Cerro Macareno. EAE, 124, 214 pp.

Rodriguez DiAz, A. (1987): El poblamiento prerromano en la Baja Extremadura. Tesis Doctoral. Universidad de Extremadura.

- (1989): «Nota preliminar sobre el poblado prerromano de Belén (Zafra, Badajoz)». XIX CAN (Castellón, 1987).

Rodríguez Díaz, A., Jiménez Avila y Domínguez de la ConCHA, A. (e.p.): «Materiales de superficie del poblado prerromano de la Ermita de Belén (Zafra, Badajoz)". Rev. Estudios Extremeños, Badajoz.

SCHULE, W. (1969): Die Meseta-Kulturen der Iberischen Halbinsel. Berlín.

SiLva, C. T. DA (1978): «Ocupaçao do Ferro da Pedra da Atalaia (Santiago do Cáçem)». Setubal Ar. queológica, IV, 117-132.

SoARES, J. y Silva, C. T. DA (1979): "Cerámica pré-romana de Miróbriga (Santiago do Caçem)». Setubal Arqueológica, V, 159-184. 